Review

\title{
Automatic Number Plate Recognition:A Detailed Survey of Relevant Algorithms
}

\author{
Lubna $^{1}{ }^{1}$, Naveed Mufti ${ }^{2, *}$ and Syed Afaq Ali Shah ${ }^{3}$ \\ 1 Department of Telecommunication Engineering, University of Engineering and Technology, \\ Peshawar 25000, Pakistan; Lubnaxafi@gmail.com \\ 2 Department of Telecommunication Engineering, University of Engineering and Technology, \\ Mardan 23200, Pakistan \\ 3 Department of Information Technology, Media and Communications, Murdoch University, \\ Murdoch 6150, Australia; Afaq.Shah@murdoch.edu.au \\ * Correspondence: Naveed@uetmardan.edu.pk
}

Citation: Lubna; Mufti, N.; Shah, S.A.A. Automatic Number Plate Recognition:A Detailed Survey of Relevant Algorithms. Sensors 2021, 21, 3028. https://doi.org/ $10.3390 / \mathrm{s} 21093028$

Academic editor: M. Hassaballah

Received: 17 March 2021

Accepted: 21 April 2021

Published: 26 April 2021

Publisher's Note: MDPI stays neutral with regard to jurisdictional claims in published maps and institutional affiliations.

Copyright: (c) 2021 by the authors. Licensee MDPI, Basel, Switzerland. This article is an open access article distributed under the terms and conditions of the Creative Commons Attribution (CC BY) license (https:// creativecommons.org/licenses/by/ $4.0 /)$.

\begin{abstract}
Technologies and services towards smart-vehicles and Intelligent-Transportation-Systems (ITS), continues to revolutionize many aspects of human life. This paper presents a detailed survey of current techniques and advancements in Automatic-Number-Plate-Recognition (ANPR) systems, with a comprehensive performance comparison of various real-time tested and simulated algorithms, including those involving computer vision (CV). ANPR technology has the ability to detect and recognize vehicles by their number-plates using recognition techniques. Even with the best algorithms, a successful ANPR system deployment may require additional hardware to maximize its accuracy. The number plate condition,non-standardized formats,complex scenes,camera quality,camera mount position,tolerance to distortion,motion-blur,contrast problems,reflections,processing and memory limitations,environmental conditions,indoor/outdoor or day/night shots,software-tools or other hardware-based constraint may undermine its performance. This inconsistency,challenging environments and other complexities make ANPR an interesting field for researchers. The Internetof-Things is beginning to shape future of many industries and is paving new ways for ITS. ANPR can be well utilized by integrating with RFID-systems,GPS,Android platforms and other similar technologies. Deep-Learning techniques are widely utilized in CV field for better detection rates. This research aims to advance the state-of-knowledge in ITS (ANPR) built on CV algorithms;by citing relevant prior work,analyzing and presenting a survey of extraction,segmentation and recognition techniques whilst providing guidelines on future trends in this area.
\end{abstract}

Keywords: automatic number plate recognition; image processing; computer vision; machine learning; vehicle identification; neural networks; intelligent transportation system; smart vehicle technologies; object detection and tracking; recognition

\section{Introduction}

Automatic Number Plate Recognition has become part of our lives and promises to stay in future, integrable with proposed transportation technologies. The concept of Autonomous Vehicles is offering many possibilities of changing fundamental transportation systems. ANPR technology is already contributing towards intelligent transportation systems and is eliminating the need of human intervention. It is no longer just the camera on the roadside or at the barrier to the car park. It has become over the years mobile, first being deployed in vehicles, but now more recently with the advent of smart phone technology, many ANPR systems have become handheld too. Due to lower provisioning costs, ANPR is often a choice in the toll and parking lot businesses. The main reason is that the ANPR system recognizes the registered number plate with no additional transponder requirements, as compared to the Ultra High Frequency-Radio Frequency Identification (UHF-RFID) systems. The rapid urbanization of countries is a great advancement in our 
modern world. People migrate away from rural areas and choose to live in cities mostly. Local governments often fail to recognize the present and potential mobility needs of residents and visitors as traffic rises in these areas. ANPR is being increasingly used to examine the free flow of traffic, facilitating the intelligent transportation [1].

Not only can modern ANPR cameras read plates, but they can provide useful additional information such as counting, direction, groups of vehicles and their speed. The ability to detect and read large volumes of fast moving vehicles has meant that ANPR technology has found its way into many aspects of today's digital landscape. Whilst ANPR technology can come in many different packages, they all perform the same basic function which is to provide a highly accurate system of reading a vehicle without human intervention. It is utilized in very diverse applications such as access control, parking management, tolling, user billing, delivery tracking, traffic management, policing and security services, customer services and directions, the red light and lane enforcement, queue length estimation, and many other services [2-8]. Figure 1 shows the basic system diagram of a fixed and mobile ANPR technology.

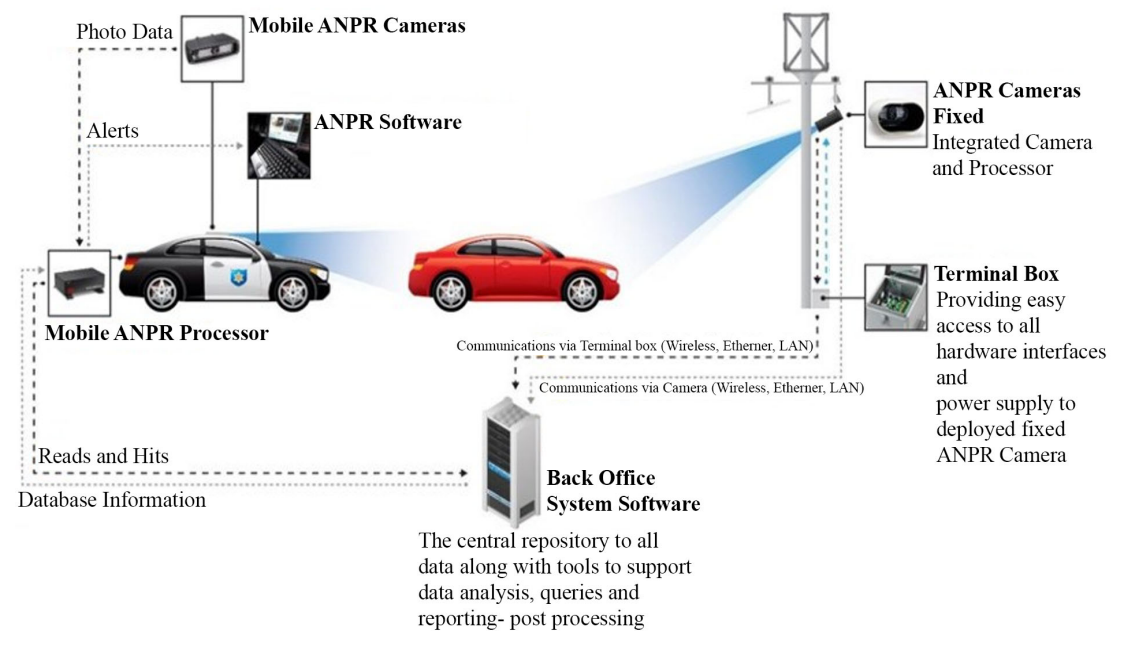

Figure 1. Typical ANPR System Diagram of a Fixed ANPR System (right) and a Mobile ANPR System (left) (Source: latech.us, accessed on 5 November 2020).

Number Plate Recognition involves acquisition of number plate images from the intended scene, using a camera. Either still images or a photographic video is captured and further processed by a series of image processing based recognition algorithms to attain an alpha-numeric conversion of the captured images into a text entry. After obtaining a good quality image of the scene/vehicle, then the core dependence of any ANPR system is on the robustness of its algorithms. These algorithms need a very careful consideration and require thousands of lines of software coding to get desired results and cover all system complexities. As a whole, a series of primary algorithms are necessary for smart vehicle technologies and ANPR to be effective. The general processes involved in ANPR systems is shown in Figure 2.

A typical ANPR system goes through the general process of image acquisition (input to the system), number plate extraction (NPE), character segmentation (CS) and character recognition (CR) (as output from the system) [9]. After successful recognition of the vehicle the data can be accessed and used for post processing operations as required. The vehicles data is sent to the connected back office system software which is the central repository to all data along with tools to support data analysis, queries and reporting accordingly. This data collected can be utilized for several other intelligent transportation applications since ANPR systems not just visually capture the vehicle images but also record the metadata in their central repository. This can potentially include vehicle recognition through date and time stamping as well as exact location, whilst storing a comprehensive database of 
traffic movement. This data can be helpful in modelling different transport systems and their analysis.

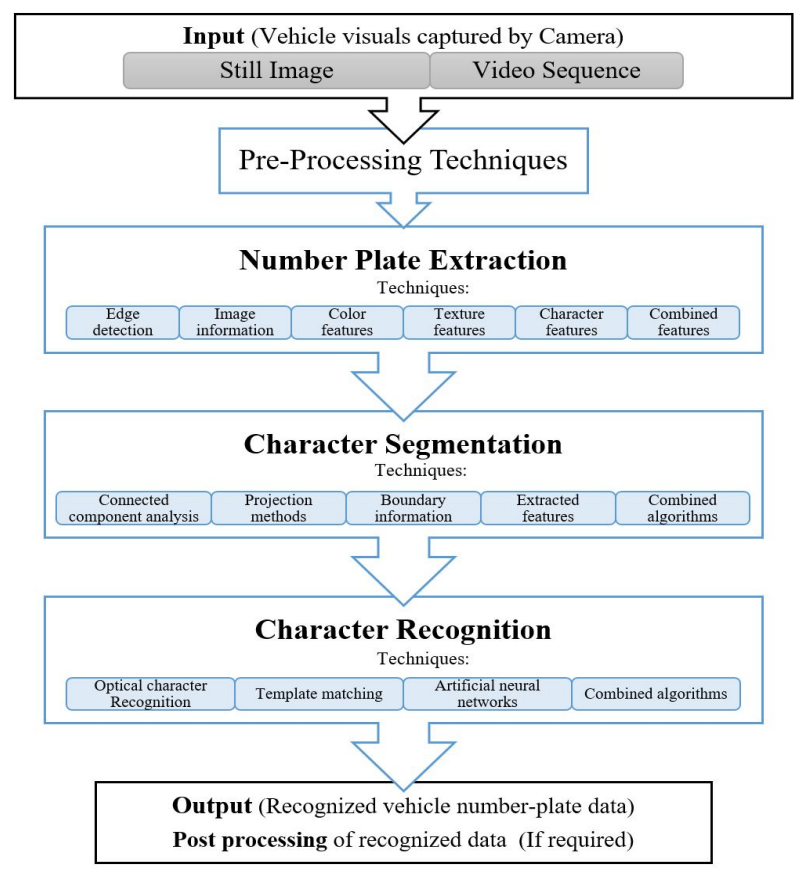

Figure 2. General processes of number plate recognition system.

The image taken from the scene may experience some complexities depending upon the type of camera used, its resolution, lightening/illumination aids, the mounting position, area/lanes coverage capability, complex scenes, shutter speed and other environmental and system constraints. Figure 3 shows License plate diversity in styles, colors, fonts, sizes, and physical conditions; which may affect the recognition accuracy. When a vehicle is detected in the scene/image, the system uses plate localization functions to extract the license plate from the vehicle image, a process commonly termed as Number Plate Extraction. Characters on the extracted number plate are then segmented prior to recognition process. Character segmentation is an algorithm that locates the alpha numeric characters on a number plate. The segmented characters are then translated into an alpha numeric text entry using the optical character recognition (OCR) techniques. For character recognition, algorithms such as template matching or neural network classifiers are used. The performance of an ANPR system relies on the effectiveness of each individual stage. A parameter used to quantify the whole process is the performance-rate or success-rate, which is the ratio of the number of number-plates successfully recognized to the total number of input images taken. The performance rate involves all the three stages of recognition process, number plate extraction, segmentation and character recognition.

The ANPR system collects the primary form of the information from ANPR software including the images and its associated metadata. It provides the transport system with automation and security features. Its integration in ITS makes it possible to automate the system by providing services in toll collections, traffic analysis, improving law enforcement's and building a comprehensive database of traffic movements. Integrating ANPR with Information Communication Technology (ICT) tools is another useful feature of the technology. The data from ANPR systems can be well utilized for modelling and implementation of various aspects of transport systems such as to model Passenger Mobility systems [10], traffic flow analysis and road network control strategies using Network Fundamental Diagram (NFD) models [11], in vehicle routing choice model to decide on Route and Path Choices of Freight Vehicles [12] and travel demand patterns through Floating Car Data (FCD) [13]." 


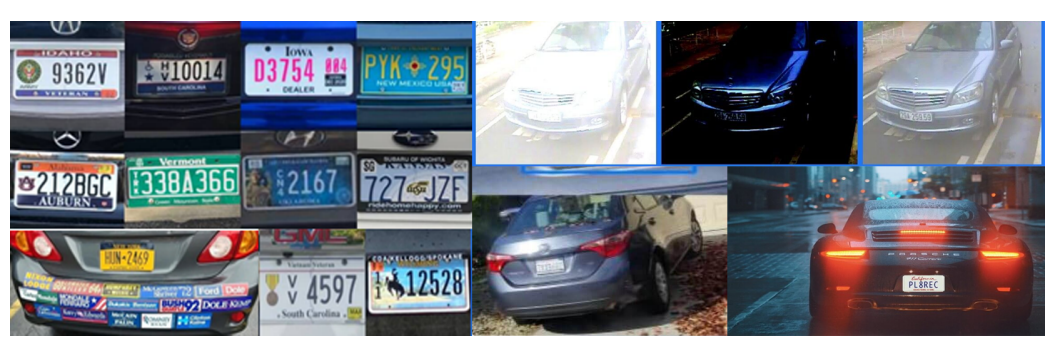

Figure 3. License plate diversity in styles, colors, fonts, sizes, and physical conditions. (Source: Plate Recognizer ALPR [14]-a division of ParkPow [15]).

There are different terminologies used for ANPR systems:

- Number plate Recognition (NPR)

- Automatic License Plate Recognition (ALPR)

- $\quad$ License Plate Recognition (LPR)

- $\quad$ License Plate Recognition (LPR)

- Automatic Vehicle Identification (AVI)

- Car Plate Recognition (CPR)

This paper provides a systematic review of the existing ANPR techniques. It covers the main features of ANPR systems by analyzing their performance summary, pros and cons accordingly. This research aims to advance the state of knowledge in smart vehicle technologies for future researchers by:

- Providing a detailed knowledge on past and current algorithms for Automatic number plate recognition systems

- Analyzing and presenting a survey of ANPR image processing based techniques for each stage systematically, (Number plate: Extraction, Segmentation followed by Recognition), with relevant brief of the techniques used at each stage along with the performance summary, where applicable

- Summarizing the performance of different algorithms used and tested by various researchers for vehicle recognition

- Summarizing previous reviews and surveys related to ANPR, as in Table 1

- Providing the performance summary with analysis and limitations, as in Table 2

- Providing list of useful ANPR datasets which the researchers may utilize to test their algorithms, as in Table 3

- Discussing current and future trends in the area of ANPR

- Discussing and citing relevant prior work for all ANPR techniques listed

Number plate extraction methods are categorized in Section 2. Number plate Segmentation and Recognition Methods are discussed in Sections 3 and 4, respectively. Discussion is provided in Section 5. Conclusion and future research directions are presented in Section 6.

Table 1 summarizes previous reviews and surveys related to ANPR [16-19]. Table 2 presents performance summary of ANPR system techniques considering their relevant performance parameters. Table 3 enlists some of the available ANPR datasets to the research community.

\section{Number Plate Extraction Methods}

Successful extraction of number plate from the image/video is initially the most important and critical stage for ANPR systems. The extraction rate is the rate of successfully extracted plates to the total number of input images or vehicles detected from the scene. Typically, a single camera is installed on each lane and some advanced cameras may allow multiple lane support given their high resolutions. Multiple lanes installation requires multiple readers to identify vehicle number plates and more hardware with higher costs to service and maintain. Real time scenarios may face multiple challenges. For instance, the camera installed at a fixed position may acquire images of the vehicle with tilted or skewed 
number plate characters. It is possible that number plate is obscured with dirt or broken or located at position that is out of sight to the camera (since different types of vehicles have their number plates affixed at different positions of the vehicle body). Environmental factors, light, motion blur, reflections, fog, and other similar conditions makes it challenging for the system to extract the number plate efficiently. Algorithms using geometrical features for extracting the rectangular shaped number plates may have issues if there are multiple similar shapes drawn/pasted over the car body. Along with rectangular shaped features, further algorithms must be used to eliminate the unwanted regions.

The algorithms need to be robust to differentiate between the number plate and other objects in the image frame. Researchers have used various features for the extraction of number plates. A brief study of these feature extraction algorithms is presented in the following section.

\subsection{NP Extraction Using Edge Information}

The number plate typically has a known aspect ratio and a rectangular shape. In [19], the images were first scaled to a fixed aspect ratio. The authors evaluated and put to test various algorithms from the past proposed research in [20-22] and compared the results by implementing it for their own dataset. One of the number plate extraction methods they evaluated is based on the vertical edge information. It detects the vertical edges using Sobel operator. The number plate is localized by comparing the preset minimum and maximum lengths with that of the extracted edges and removing the unwanted ones. The total extraction rate for 141 images is $65.25 \%$ which is lower than the $99.99 \%$ originally reported in [20]. In [23], vertical and horizontal edge histogram information is used for number plate extraction. Testing 50 images of various fonts and light conditions resulted in $90 \%$ extraction accuracy.

Edge detection algorithms are commonly used to extract number plates by finding all the rectangles in the acquired images [24-26]. Mostly, the car body and number plate area have a clear color transition. The differentiation between the two is done by identifying the edges using edge detection filters or algorithms. Sobel filter, a simple algorithm, has been used for the successful edge extraction as presented in $[19,20,27,28]$. Edges are detected by performing vertical edge detection to extract the vertical lines and horizontal edge detection to get the horizontal lines or simultaneous use of both to extract a complete rectangular shape. The number plate can be detected by using the geometric attributes by locating the rectangle lines. Various edge detection filters Sobel, Canny, Gabor \& Log-Gabor filters for ANPR systems are compared in [29].

Gabor filters are considered the best choice for structure recognition as they show exceptionally good results for excluding clamor/noise while saving edges [30].

In $[20,27,31]$, the indented number plate region is extracted by using the magnitude of vertical edges, and this is considered as the most robust extraction feature. The vertical edges are compared to acquire the intended rectangles which are then filtered for the one rectangle being the number plate area using the known aspect ratio. In [20], it is stated that if the background edges are removed and the vertical edges are obtained, the number plate can be successfully extracted from the remaining edges in the image. The total processing time for an image of size $384 \times 288$ is $47.9 \mathrm{~ms}$ and the detection rate was about $100 \%$ for 1165 test images.

Vertical Edge Detection Algorithm (VEDA) is said to be the robust algorithm for edge detection as proposed for number plate extraction in [32]. The extraction rate for 50 images in various lighting conditions is $96 \%$. The horizontal edges can result in possible errors. These errors occur mainly due to the car bumper [33]. From the literature, we can also find the block-based method for this purpose. According to [34], the possible number plate areas are the blocks having the high edge magnitude. This method is independent of the boundary edges of the number plate and can be applied to identify it from unclear images too. An accuracy of $92.5 \%$ is obtained for character recognition, using a pair of 180 different images. In [35], tests were carried out to check the inspection status of motorcycles by 
recognizing its number plate. A success rate of $95.7 \%$ for roadside and $93.7 \%$ for inspection stations test images was achieved. In [36], Hough Transform is used to extract the number plate using the boundaries. The number plate is located by detecting straight lines in the test image. This transform has the ability to detect straight line with an inclination of up to 30 degrees. However, it is computationally expensive and requires large memory. In [37], the generalized symmetry transform is used. The corners from the edges in the image are detected by scanning them in selective directions. By using the generalized symmetry transform the number plate region is extracted by detecting the similarities between these corners. The continuity of the edges is important when using the edge based methods as these are considered to be simple and fast. The extraction rate can significantly improve by eliminating the unwanted edges using some morphological steps. A combination of morphology and the edge statistics was proposed in [38]. Prior to this, the basic pre-processing techniques were also applied to enhance the image for color contrast and noise removal. $98 \%$ of successful extraction and $75-85 \%$ overall performance rate is achieved by testing on 9745 images.

\subsection{NP Extraction Using Global Image Information}

In binary image processing, the image is scanned and its pixels are labeled into components based on the pixel connectivity using the Connected Component Analysis (CCA) technique [39-41]. In [42,43], for extraction of number plate, the spatial measurements are used which are commonly the aspect ratio and area.

Slimani et al. [39] proposed a two-step method for the number plate extraction. To cope with the variant light illumination conditions, the first step uses Otsu's Threshold Method which is an efficient and simple method for adaptive thresholding techniques. The binarized image is then detected for rectangular shapes in it using the CCA technique. The second step applied to the obtained number plate is to perform the edge detection followed by closed curve method to make sure that the generated image is a number plate. Over 2500 Moroccan format images from video sequences were tested using this method with a success rate of $96 \%$. The connected component analysis technique used in [43] recorded a successful extraction rate of $96.6 \%$ on a low-quality video with a length of over four hours. Contour detection techniques are used on binary images to locate the connected objects [44]. The geometrical features having similarity with the number plate is chosen for further processing. However, this algorithm may result in distortion errors if the acquired image is of low quality.

In [45], cross correlation is used for the same task. To extract the number plate region, a pre stored number plate template is used while performing the 2D cross correlation, making it independent of its position in the image. However, it is considered to be a time-consuming method.

\subsection{NP Extraction Using Color Features}

Vehicle number plates can be color specific for some regions or countries. As we study the work reported till date, color based extraction of number plate from the image is also tested for ANPR systems.

General approach of number plate extraction involves the idea of color combination of the number plates. Also, the characteristics are unique, and such color contrasts take place solely in a plate region. Shi et al. [46] proposed a technique for the specific patterns of Chinese number plates. Their technique employed all pixels from the acquired image and then grouped in terms of hue, lightness, and saturation (HLS). The HLS color model classifies the pixels into 13 color categories instead of 6 RGB divisions. Color model was used instead of grayscale. The color division selection is made according to China Mainland number plate formats. In their experiment, $90 \%$ of the total images were correctly recognized in various illuminations.

In [47], recognition of only certain colors including black, green, white, and red-are used in number plates, color edge detectors work only on three types of colored edges 
including red-white, black-white, and green-white combinations. While experimenting under different conditions, about 1088 images were analyzed from various scenarios. The localization rate of number color plate is $97.9 \%$. In [48], to classify each pixel color, a neural network is utilized after transforming the true color image into hue, saturation, lightness (HLS) color model. Neural network outputs the white-green-red colors being the specific colors used in Korean number plates. To detect the region of highest color density, the same color combination is projected both horizontally and vertically in the number color plate.

To create an edge image, the combination of character color as well as number plate color is used in [49]. The image generated is then scanned horizontally. In case any pixel having value within the range of the number color plate exists, the color range of its horizontal neighbors is examined. If minimum two or more than two horizontal neighbors belong to the same range, then that pixel is termed as the edge pixel. Eventually, all the edges are analyzed in the new edge image, which is done to determine the color plate regions.

In [50,51], mean shift algorithm is applied for segmenting the color images into candidate regions. Later on, these candidate regions are labeled as either a number plate area or discarded. A detection rate of $97.6 \%$ accuracy was recorded. In [52], another algorithm namely, a fast-mean-shift method was proposed. Mean Shift method is widely used in feature analysis including image and video segmentation. The authors utilized the feature of segmenting the complex background into possible segments and thus extracting the candidate number plate region. A database of 400 images, captured under various light conditions having $640 \times 480$ pixels size, were tested using the proposed method. A detection accuracy of $92.6 \%$ was achieved.

To deal with the varying illuminations problems, [53] came up with an algorithm based on fuzzy logic. The HSV color space is utilized in the process. In the fuzzy sets, all the components of HSV are initially mapped in terms of the different membershipfunctions. Then the fuzzy classified function is demonstrated by fusing all the three HSV components based weighted membership degrees. Three different image datasets were chosen for testing the efficiency. The recognition rate on average as recorded is $95.05 \%$ on Shanghai, $92.17 \%$ on Shenzhen and $93.23 \%$ on Beijing number plates respectively. In [54], to determine candidate regions, the statistical threshold is chosen by the adopted color model of HSI, where HSI represents Hue, Saturation, and Intensity. This technique can be utilized to detect candidate regions provided the number plates and the car/vehicle bodies are of the same color. The standard deviation and mean of hue are applied in the detection of yellow and green pixels of number plate. The intensity and saturation component of HSI are utilized for sending the white, green, and yellow pixels of number plate from the relevant vehicle images.

There is an advantage of applying number plate extraction method by using color information. That is, you get to determine the number plates that are either deformed or inclined. However, it comes with some drawbacks as well. It is challenging to define the color of the pixel using the RGB value, particularly under specific conditions of illumination. The HLS color model [48], which is used as a substitute, is quite noise sensitive. Methods that work on color projection deal with the drawback of incorrect detection of the image parts that have the exact color on the number plate as the car body.

\subsection{NP Extraction Using Texture Features}

These methods are dependent on the characters in the number plate area. A grey scale shows a significant change due to color transition with a high edge density between the character colors on the plate and its background.

Local Binary Pattern (LBP) [55] and Histogram of Oriented Gradients (HOG) [56] are used in [36], for number plate extraction. Considering the rectangular shape of the number plate, along HOG, the LBP algorithm is used for classifying the texture and calculating a histogram. The accuracy of locating 110 images is $89.7 \%$. However, this technique is not useful for images with blur or low light conditions and different angle orientations. 
Another effective technique for plate detection used by many researchers is to utilize the line weight density map. This can be combined with other techniques to improve results. In [49,57-63], the scan line technique is utilized where the peaks are formed from the color transition of the grey scale level which corresponds to the number of characters on the number plate. In [57], the authors proposed the horizontal line scanning with multiple thresholds technique for plate detection in a real time/complex images. The experimental results were compared to the conventional model based on Hough transforms with low detection accuracy of $69.8 \%$ and longer processing time of $8-10 \mathrm{~s}$, as in [58]. In comparison to [58], the extraction rate of $99.2 \%$ was achieved using line scan technique in [57]. The execution time for locating the plate was incredibly reduced to $0.3-0.5$ s comparatively.

In [59], the edge lines were selected using a weight density map. This technique was implemented on a certain set of images and the results were effective with an extraction rate of $93 \%$, whereas for different image standards the effectiveness dropped to $83 \%$. In [60], the weight density map is combined with neural network based algorithms. A dataset of 400 varying conditions images were tested. This hybrid approach proved to be effective, with a success rate of $97.23 \%$ and average extraction time of $0.0093 \mathrm{~s}$ per image, based on simulations results. In [49], the authors used histogram data with combined features of morphology. $97.7 \%$ success rate is recorded for 360 images set under different conditions. Vector quantization technique is used to detect the characters in the image by mapping the higher contrast regions into smaller blocks. Using different quality images, it yielded $98 \%$ of successful detection with a processing time of $200 \mathrm{~ms}$ [64].

The use of sliding concentric window was proposed in [54,65]. It uses the texture irregularities in the image. The area with abrupt changes is considered to be the candidate number plate region. In [54], histogram was used along with the sliding concentric window method. Texture analysis is widely used for number plate extraction. Gabor filters being the candidate tools had the ability to analyze textures in any number of orientation and scales [66]. It is, however, a computationally expensive method. While using fixed and specific angled images, it resulted in a $98 \%$ success rate [67].

Wavelet transform is used in [62,68]. In [62], horizontal reference lines with wavelet transform processing achieved a success of $92.4 \%$. In [68], using wavelet transform, an accuracy of $97.3 \%$ is achieved with a processing time of $0.2 \mathrm{~s}$. A combination of Haar-like features and adaptive boosting is used in $[69,70]$. This feature is commonly used to detect objects and is invariant to the position, size, contrast or color of the number plate. The gradient density is used by the cascade classifiers in [69], with a detection success of $93.5 \%$. With adaptive boosting technique, images of different sizes, formats and with various illumination conditions, yielded $99 \%$ detection rate [71].

Texture based techniques are independent of the number plate boundary and can detect number plate properly even if it is deformed. However, these techniques are computationally complex to extract number plate from such images, if too many edges are detected in the image or the background has multiple elements, or the light illumination is not enough.

\subsection{NP Extraction Using Character Features}

Techniques based on character feature extraction are also proposed in various research studies, which are associated with locating the plate's characters. These methods scan the image for characters on the number plate, if any. The region where the relevant characters are identified, is then extracted as number plate region. In [72], the algorithm identifies all the character areas from the image rather than directly applying the number plate properties. This process is executed by using the character-like region dependent approach. All the identified character-based regions are mentioned and classified using neural network. In [73], the aspect ratio of binary image objects is the same as that of the characters and around 30 image pixels are labeled. Hough transformation is used to identify the straight lines. The same transform is applied to both upper and lower parts of these binary labeled objects. When two lines are parallel to each other and lie within a 
specified range and has the same number of objects as the characters, the region between these lines is termed as the number plate area. In [74], the scale-space analysis is used to extract the number plate characters. This technique extracts blob type large sized figures that include line type of smaller figures as character candidates. In [75], firstly, the regions containing characters are identified in terms of the character width and the difference between character region and its background. Then the number plate extraction process is executed in the plate region to identify inter-character distance. This extraction technique produces an extraction accuracy of about $99.5 \%$. In [76], the first stage character classifier obtains a primary set of all the possible character-like regions. Then the set is passed to the next stage classifier. This second stage classifier process eliminates the non-character regions from the initial set. In this technique, 36 AdaBoost classifiers act as primary stage classifier. The second stage classifier is employed with Support Vector Machine (SVM), which uses Scale-Invariant Feature Transform (SIFT) algorithm, to detect and describe local features of number plate images. These techniques of feature extraction from binary images, to define the number plate region, take quite long time. The reason is attributed to the processing of all the objects from those binary images. These processes also generate errors if the image contains other texts on it.

\subsection{NP Extraction Using Feature Learning}

For effective detection of number plate, few extraction methods look for at least two or more characteristics of the number plate. In this case, the extraction techniques are considered as hybrid extraction methods [77].

You Only Look Once (YOLO), a Convolutional Neural Network (CNN) based object detector, has been utilized in [78]. It is a two-step method that employs easy data augmentation strategies like flipped characters and inverted number plates. The CNNs are fine-tuned and trained at each stage. The resulting model yields good results for two distant datasets. The first database SSIG-SegPlate Database by Smart Surveillance Interest Group (SSIG), includes 2000 frames from about 101 vehicle videos. The system achieves $93.53 \%$ recognition accuracy at 47 FPS, functioning better than both the commercial systems of OpenALPR and Sighthound (with respective recognition rates of $93.03 \%$ and $89.80 \%$ ), and substantially better results than the past techniques $[79,80]$, which achieve accuracy of $81.80 \%$. The other dataset used has varying image conditions, similar to real time scenarios. This public database is termed as UFPR-ALPR. The UFPR-ALPR dataset is the property of the Laboratory of Vision, Robotics and Imaging (VRI) at the Federal University of Paraná, Brazil) dataset. It contains around 4500 frames and 150 videos taken while both the vehicles and camera are in motion. The dataset contains several types of vehicles including buses, motorcycles, cars, and trucks. The test versions of commercial systems yielded the rate of recognition which is less than $70 \%$ while this system functions well with 35 FPS and identification rate of $78.33 \%$. Bulan et al. [81], attained greater accuracy in $\mathrm{NP}$ recognition adjacently implementing the character recognition and segmentation with Hidden Markov Models (HMMs). Here, the most probable NP was decided by running the Viterbi algorithm.

Extraction of texture and color features are combined in [82-86]. In [82], rules from fuzzy logic method are used to extract yellow colors and texture feature. The color values of yellow, obtained from the demo images, are employed to train color feature fuzzy classifier. This fuzzy classifier is trained according to the color transition between number plate background and characters. Each of the pixels is classified, for any given image, if it belongs to the fuzzy rules generated number plate. In [83], two neural networks are employed for determining the color and texture characteristics. One of the neural networks is trained for texture detection using several edges within the plate area. The other is employed for color detection. These neural networks' outputs are used in identifying the candidate regions.

In [84], there is a single neural network utilized for image scanning with $\mathrm{H} \times \mathrm{W}$ window, which resembles the size of vehicle plate. This network is used to sense the 
edges and color within this window to determine if it is a candidate area containing number plate. In [85], the neural network horizontally scans an HLS image with a $1 \times \mathrm{M}$ window. Here, $\mathrm{M}$ represents an approximate width value of the number plate, and vertical scanning is done with an $\mathrm{N} \times 1$ window, where $\mathrm{N}$ indicates the height of the plate. For every pixel of the image, the hue value is used to denote the color details and intensity value represents the texture details. Resultant of both the horizontal and vertical scans is combined to extract the candidate areas of the plate. In [86], Time-Delay Neural Network (TDNN) is processed for number plate extraction. Two such TDNNs are implemented in the color and texture analysis of the number plate by checking small windows of the image's horizontal and vertical cross sections. Based on pixel values similarity with the number plate, the area with higher edge density is extracted as a number plate. Edge and color information based approach is used for extraction in [87]. Covariance matrix has been used for plate extraction in [88]. It is based on combining the spatial information and statistical data. Each matrix has adequate amount of information and it is enough to match the area in multiple views. This matrix is used to train the neural network efficiently in order to detect the number plate area. A combination of texture shape and color features is used in [89]. The number plate extraction from 1176 images shows extraction rate of $97.3 \%$, considering various light illumination condition and scenes. Connected Component Labelling (CCL), threshold and Gabor filter are combined in [66] to extract number plates. To detect edges, wavelet transform is used in [87]. This is done by employing the morphology techniques once edges are detected. The shape and structure information analyzed from the input images is helpful to localize the number plate. HLS color decomposition, Hough detection and wavelet analysis are proposed in [90]. In [91], two-dimensional Discrete Wavelet Transform (DWT) is used. The proposed method successfully eliminates the background noise by highlighting the number plates' vertical edges. The plate extraction was done using orthogonal projection histogram inspection and Otsu's segmentation. The most accurate candidate is then chosen on the basis of edge density verification and aspect ratio constraint. In [92], the number plate detection is done by Modified Census Transform (MCT) computed local structure patterns. After that, two post-processing parts are utilized to reduce the incorrect positive rates. One post-processing includes the position-based technique between a vehicle plate and a false positive that has indifferent local structure patterns like radiators or headlights. The other one is the color-dependent method that utilizes entire color details of the number plates. Deep Learning (DL) techniques based ANPR systems generally address the character identification and segmentation as a whole. Montazzolli et al. [93] proposed a CNN architecture for character segmentation and recognition. The experiment was carried out using a publicly available dataset. In their technique, $99 \%$ of the characters were segmented successfully while the accuracy of reading the segmented characters was $93 \%$. However, in spite of the outstanding achievements of DL techniques in ANPR $[79,94,95]$, ANPR datasets with cars/vehicles and NPs annotations still have a huge demand. The training data set is responsible for the progressive performance of DL methods. A huge training data will help in the training of data hungry deep neural networks and better utilization of more robust network architectures along with additional layers and parameters.

\section{Number Plate Segmentation Methods}

The character segmentation stage is totally dependent on the success of number plate extraction from the image or scene. The isolated number plate may experience issues such as contrast problems, varying illumination conditions, or it may be oriented at variable angles. In such cases, pre-processing techniques, de-skewing, de-blurring or any other methods, depending upon the conditions of the number plate, may need to be applied before segmenting the characters. This step is carried out either at the extraction stage or after getting an isolated candidate area, which depends on the approach followed. To deal with tilted number plate images, preprocessing technique like bilinear transformation is used in $[48,96]$, the isolated number plate is mapped onto a straight rectangular shape. 
Tilted number plates are fixed using a least square method in [97], it treats both the vertical and horizontal oriented tilts. In [98], using the Karhunen-Loeve (K-L) transformation, the character coordinates are organized into $2 \mathrm{D}$ variance matrix. After that, the angle of rotation and Eigenvectors are computed, and tilt correction is implemented for both vertical and horizontal tilt of the image. Three techniques namely: K-means cluster based line fitting, least squares based line fittings, and K-L transform are suggested to compute the angle of vertical tilt. Threshold application seems simple while converting to binary image, but it is a very challenging part in the whole process. An inappropriate threshold value may result in connected characters, with either within characters or with the number plate frame, which makes it difficult for segmentation [97]. A single value threshold may not be appropriate, for all the images, due to variance in image conditions and lighting. Image enhancement is necessary before binarizing the image. Enhancement includes noise removal from the image, enhancing its contrast or to apply histogram equalization techniques. In [99], to implement gradient analysis over the entire image, a technique was proposed to sense the number plate followed by the enhancement of the plate by grey color transformation. In [100], the Niblack binarization algorithm adjusts the image threshold according to the standard deviation and local mean. In [101], for every pixel, local threshold technique is applied. The threshold value is obtained by subtracting the specified constant value from the average grey levels in an $m \times n$ window placed in the middle of the pixel. In [102], a new method was proposed to reduce noise and characters enhancement. The character size was assumed to be about $20 \%$ of the size of number plate. Initially, the level of the grey scale is ranged between $0-100$. Then $20 \%$ larger pixels are scaled by a factor of 2.55. The noise pixels are minimized whereas the characters are intensified. As the image binarization is unable to generate desirable results with one global threshold, method of adaptive local binarization is followed.

In the following, number plate segmentation methods are reviewed, based on the features used.

\subsection{NP Segmentation Using Connected Components}

Pixel connectivity is used for segmentation in [23,24,26,27,45,47,103]. In [26], 958 High Definition (HD) images with various conditions are tested using connected component labeling with $99.75 \%$ segmentation accuracy. The character pixels in the binary image are labeled based on their connectivity and are analyzed for aspect ratio and size with that of the number plate characters. However, this method does not seem promising for joined characters or broken ones. In [23], a limited dataset of 50 images were tested using connected component labeling and morphological method, achieving a segmentation rate of $91 \%$. In [24], using connected components analysis, an accuracy rate of $99.5 \%$ was recorded by employing HD images in various light and weather conditions. In [45], the extracted plate area is binarized and labelled to get the numbers. To identify the labeled segment as a number, several label layout patterns were used. The overall recognition rate of the system was $99 \%$. In [47], a hybrid of connected components and blob coloring techniques was considered for segmentation. The overall accuracy of their system was $93.7 \%$.

\subsection{NP Segmentation Using Vertical/Horizontal Projection}

A number plate has different colors for characters and background. The resulting binary image has different values for both the character and background of the number plate. In [19], pixel projection in vertical and horizontal directions is used for character segmentation. Projection techniques are used in $[46,48,58,86,104-111]$. To analyze the start and end points of characters, vertical projection is applied to the binary number plate, followed by horizontal projection, in order to extract individual characters. Apart from noise removal analysis of character sequence, vertical projection is applied for character extraction in [104]. This technique reaches up to an accuracy of $99.2 \%$ with processing speed of 10-20 ms for over 30,000 images. Profile projection method used in [108] is tested on a database of 560 images. The segmentation rate of $95.4 \%$ was achieved with an efficiency 
of recognizing multiple number plates present in single images. From review, it can be concluded that the technique following both horizontal and vertical pixel projections is the simplest and commonly implemented. The projection techniques show promising results for segmentation of characters as it is not dependent on their position. However, it requires prior knowledge of the character count. Image quality and noise may affect the projection values.

\subsection{NP Segmentation Using Characters Features}

Primary knowledge regarding characters facilitates the vehicle plate segmentation process. In [112] character isolation is done using the RGB color extractor. The segmentation rate is $98.5 \%$ for 255 color images evaluated. YOLO models, YOLOv2, Fast-YOLO, and Classification-Regression Network (CR-NET) [93], which are based on neural networks, are applied for segmentation in [78]. In [28], to recognize the locations of the starting and ending characters, the binary image is scanned horizontally. If the character-pixel to background-pixel ratio surpasses the threshold level just after being below the threshold value, this is termed as beginning point of the character. Paliy et al. [113], proposed resizing of the extracted vehicle plate into a known template proportion. All the positions of the characters in this template are known. Once resizing is done, the same locations serve as the characters. This technique is known to be simple. However, in case of extracted number plate shifting, it results in background rather than characters. One possible solution for severely damaged number plates is proposed in [114]. The color combination is utilized for locating the vehicle plate from the image. Each of the character dimensions is considered for character segmentation. Chinese number plate layout is used in the construction of recognition classifier. In [115], Taiwanese vehicle plates have similar color distribution with a white background and black characters. The number of color transitions from white to black or vice versa is maximum 14 and minimum 6 when the number plate is scanned horizontally. To rectify the rotation problem, Hough transform is applied. Hybrid binarization method is applied for character segmentation of dirty number plates. Lastly, the feedback procedure is implemented to manage the parameters. Around 332 distinct images are captured at varied distances and under different illuminations for their experiments. The overall rate of segmentation and localization are $96.4 \%$ and $97.1 \%$ respectively.

\subsection{NP Segmentation Using Boundary Information}

Character segmentation can also be achieved by modeling contours. Vertical edge detection with the long edge removal is used in $[116,117]$. Closed curved technique is used in [39]. In [36], vertical histogram is used for character segmentation. In [118], the segmentation process based on an adaptive morphology approach, for extracting severely degraded number plates, is proposed. Histogram related algorithm determines the sections and merges them. In [119], the algorithm of morphological thickening is used to find the reference lines to isolate the overlapped characters from each other. The algorithm of morphological thinning detects the baseline for connected character segmentation. About 1005 images were correctly segmented from an image set of 1189 degraded images, with a segmentation rate of $84.5 \%$. In [120], a technique was demonstrated specifically for segmentation of the numerical characters on a number plate. This is done with the utilization of some dynamic programming. This method works at a quick pace by utilizing the algorithm's bottom-up approach. Moreover, this method functions robustly by reducing the features that depends on the environment like edges and color. The rate of success of identifying main numbers is $97.14 \%$.

\section{Number Plate Recognition Methods}

The final stage of ANPR systems is to recognize the segmented characters. The segmented characters may have different size and thickness due to zooming and cam- 
era distance [99]. The characters may be broken, tilted or effected by noise. Character recognition methods are covered in this section.

\subsection{Character Recognition Using Template Matching}

The simplest method for character recognition is Template Matching. It is a crosscorrelation method in which the similarity of the extracted character is compared or measured with the template characters set. The character having the highest match with one of the candidates from within the templates set is chosen. The change in lighting condition directly affects the gray level intensities in the resultant image and for this reason, these methods are commonly used for binary images.

Template Matching Technique is used to recognize the segmented characters in [39], with success rate for four different sets of Moroccan format number plates as $98.1 \%, 96.37 \%$, $93.07 \%$, and $92.52 \%$ respectively. The use of template matching technique is also presented in $[19,26,27,31,45,48,102,112,121]$. There are many similar methods available in the literature such as Bayes decision [45], Jaccard Technique [48], Hamming distance [31] and Hausdorff Distance [122]. Normalized cross correlation is used for character recognition in [123]. The extracted characters are matched with the templates by scanning them column wise. The highest correlation value shows the best matched character. However, recognition by Template Matching is only successful if the characters are not broken, not tilted, have no fonts change, and have been resized to a fixed size [97]. To address this issue [124] uses several templates stored for a single character including tilt factor considering multiple orientations.

In [117], over 1200 images with dimensions 250 pixels wide, captured under various conditions and colors, had high extraction rate of $100 \%$ and reasonable recognition rate of $90 \%$. In [125], over 1300 images of size $640 \times 480$ pixels with defined aspect ratio of license plate, are employed under various real time conditions. The extraction rate is efficient, almost $98.35 \%$, while overall system performance for recognition is $92.12 \%$, with processing time of $1.2 \mathrm{~s}$ at $10 \mathrm{FPS}$.

\subsection{Character Recognition Using Extracted Features}

Template matching technique involves all pixels which adds up to the processing time. The alternate method of feature extraction is also used for Character Recognition; it reduces processing time and eliminates the pixels of less importance [97]. SVM is used for character recognition in [126,127]. For challenging and complicated number plates, an improved SVM based algorithm is proposed in [128]. In [109,129], the features vector is produced by vertical and horizontal binary character projection. Each of the projections has undergone quantization into four specific levels, in [129]. In [109], Hoteling transformation is implemented on each character to produce the characteristic vector. This transformation is quite responsive to the segmentation output. In [47], division of binary character into $3 \times 4$ pixels' block is done, a total of 24 blocks and each with a separate value that results in the generation of a characteristic vector. Each matrix is matched to a pre-defined template of characters set and as per template matching routine the closest matched character is selected for each block. After the characters' identification, two separate groups of characters are formed and tested further using trained neural networks for improving the system recognition accuracy. Euler number and positioning check is performed for further enhancement of recognition rate. This technique took an average of $2.41 \mathrm{~s}$ to identify a Botswana number plate format and was unable to work well with vowels, angled/skewed and occluded/obscured plates. In [102], the process is quite similar to the previous, the only difference is in counting the elements having some degrees of inclination of $0,45,90$, and 135. In [130], features scanning is implemented along the axis, which is located centrally. This axis links the horizontally bound lower and upper central moment. Then the transition between the number plate characters and the background as well as the gap between them forms a characteristic vector for individual character. This technique is constant in terms of character rotation. In [131], the characteristic vector is produced by demonstrating overall 
character contouring. The output waveform is passed through quantization to get the feature vector. This technique identifies variable sized and multi-font characters as the character contour does not change with the change in any font or size. In [132], character extraction is implemented by using Gabor filter. The character edges having the same orientation angle as the filter will have highest filter response. It can be utilized to generate characteristic vector per character. In [133], to extract characters in different directions from the character image, Kirsch edge detection is applied. This detection method for character identification and extraction yielded better acceptable results than the other techniques of edge detection including Wallis, Prewitt, and Frei Chen [134]. In [135], the characteristic vector extraction is done from binary image, followed by thinning operation to turn the character strokes direction into a singular code. In [136], the grey level values of the pixels of 11 sub-blocks are applied into the classifier of neural network as the characters. In [137], a scene is examined by reaching the non-overlapped $5 \times 5$ pixels blocks, thereby processing the overall image details to extract "spread" edge characteristics as per the experiment conducted in [138]. While in [139], following the coarse-to-fine recognition approach, the sub-image classification is described. In [71], three characteristic parameters, namely: peripheral background area, contour-crossing and directional counts are utilized where an SVM is used to perceive the classification.

\section{Discussion}

Some ANPR systems may use simple image processing techniques, performed under controlled conditions for predictable license plate styles. However, dedicated object detectors-such as HOG, CNN, SVM and YOLO to name a few-are used by advanced ANPR systems. Further advanced and intelligent ANPR systems utilize state-of-the-art ANPR software based on Neural Network techniques with AI capabilities. Just like many other fields, computer vision and machine learning have applications in ANPR too. The sheer diversity of license plate types across territories, states and countries makes ANPR challenging. The fact that any ANPR algorithm will need to work in real time further complicates Number Plate identification. Hence, utilizing ML, CV, AI techniques can relevantly empower ANPR.

Previous reviews from Literature are presented in Table 1. The cited works reviewed various techniques for each stage of ANPR system. The authors in [17] provided a good references collection for the new researchers in license plate detection field. However, the research did not compare the performance of recognition techniques in terms of accuracy rates.

The authors in [18] discussed the performance of the various algorithms used in the past. The percentage efficiency of the ANPR system per year was presented for years 19992015. The conclusions included that the efficiency of the ANPR system is not stable, and the performance varies due to various factors affecting ANPR like noise, environmental condition, choice for the algorithms and models training. 
Table 1. Previous Reviews from Literature.

\begin{tabular}{|c|c|c|}
\hline Year & From & Techniques Reviewed \\
\hline 2018 & [16] & $\begin{array}{l}\text { Reviewed Myanmar Researched Papers Only. } \\
\text { - Khin et al. in the year } 2018 \\
\text { - } \quad \text { Threshold based approach and bounding box } \\
\text { - } \quad \text { All colors, and conditions images are used } \\
\text { - } \quad \text { Neural et al. in the year } 2016 \\
\text { - } \quad \text { Noisy, tilted plates or other degraded forms of number } \\
\text { - } \quad \text { Very limited number of samples tested } \\
\text { - Sinha et al. in the year } 2011 \\
\text { - } \quad \text { Character extraction and recognition } \\
\text { - } \quad \text { Pattern recognition based on fuzzy logic } \\
\text { - Did not yield good results for skewed plate } \\
\text { - } \quad \text { Hybrid Approach in the year } 2004 \\
\text { - } \quad \text { Edge detection and morphological operations } \\
\text { - } \quad \text { Tilted/skewed characters are not tested }\end{array}$ \\
\hline $\begin{array}{l}\text { ine } \\
2017\end{array}$ & [17] & 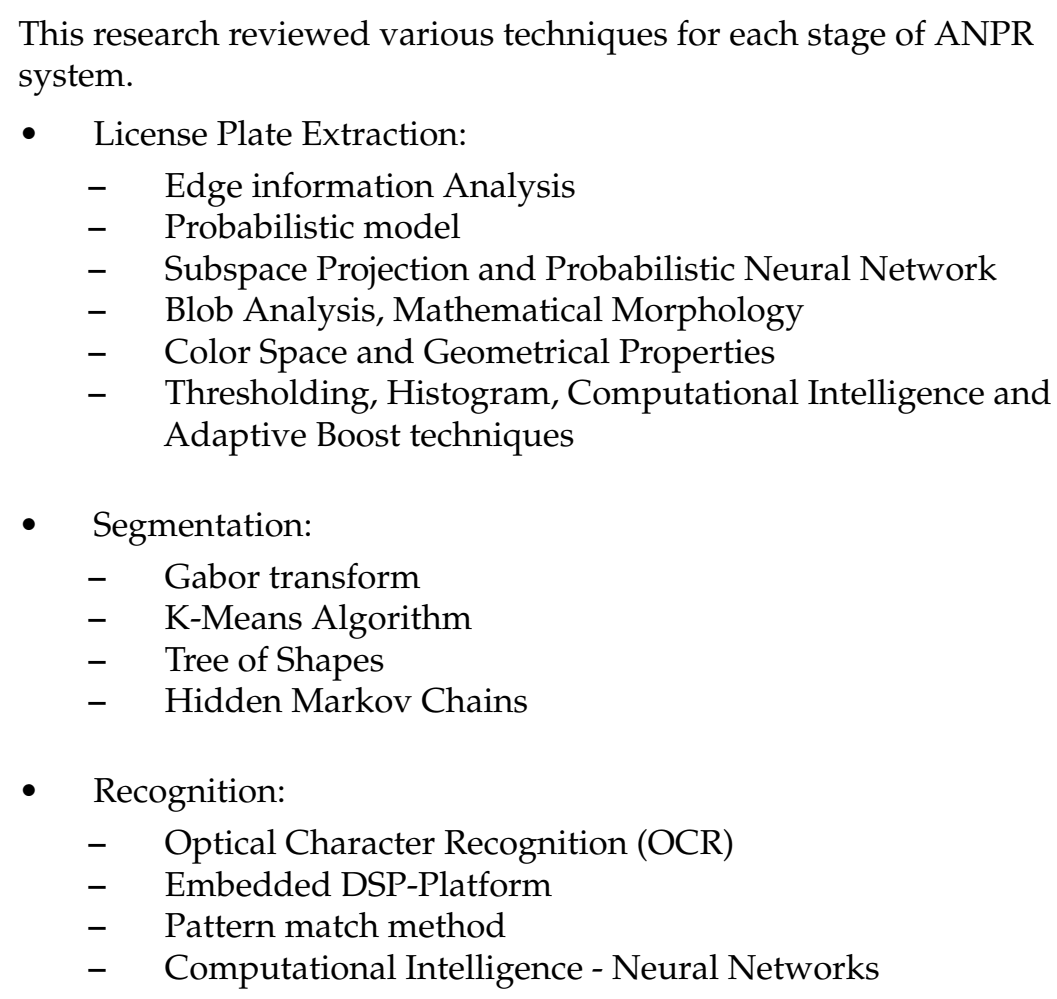 \\
\hline 2016 & [18] & $\begin{array}{l}\text { Reviewed techniques: } \\
\text { - Feature salience, Hough Transform, Neural Networks, His- } \\
\text { togram techniques, Chin code, Tophat Filtering, Template match- } \\
\text { ing, Matrix mapping, wavelet transform, SVM, Pulse Coupled } \\
\text { Neural X Networks, SIFT feature points, Gaussian Filtering and } \\
\text { other modified NNs. }\end{array}$ \\
\hline
\end{tabular}


Table 1. Cont.

\begin{tabular}{|c|c|c|}
\hline Year & From & Techniques Reviewed \\
\hline \multirow[t]{2}{*}{2015} & [19] & 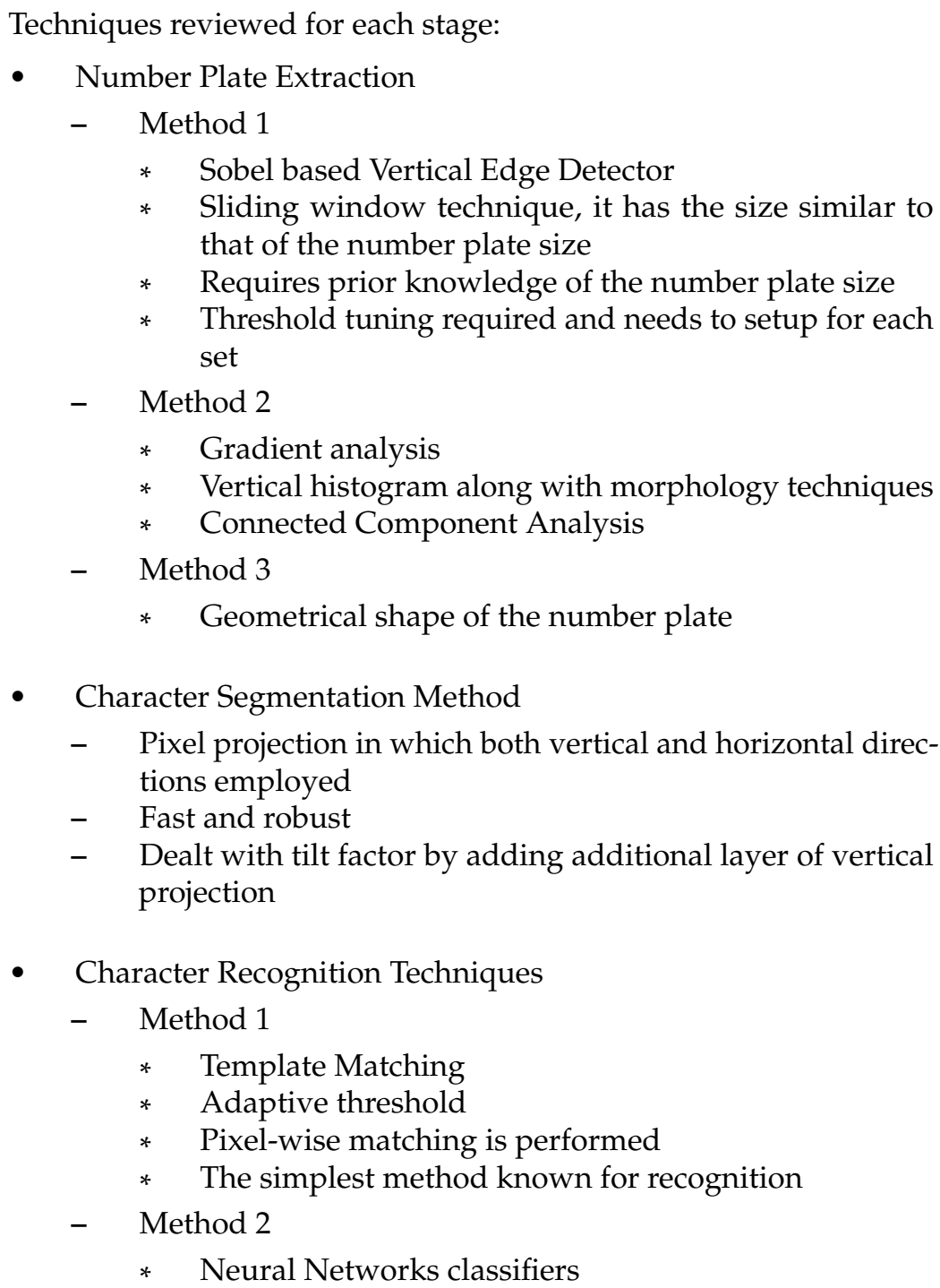 \\
\hline & & $\begin{array}{l}\text { The performance of these techniques reviewed is summarized in } \\
\text { Table } 2 \text {. }\end{array}$ \\
\hline
\end{tabular}


Table 2. Performance Summary of ANPR system techniques.

\begin{tabular}{|c|c|c|c|c|c|c|c|c|c|c|c|c|c|c|c|}
\hline No. & From & Extraction & $\begin{array}{l}\text { Procedure } \\
\text { Segmentation }\end{array}$ & Recognition & Database & $\begin{array}{l}\text { Image } \\
\text { Condition }\end{array}$ & $\begin{array}{c}\text { Extraction } \\
\text { Rate }\end{array}$ & $\begin{array}{c}\text { Segmentation } \\
\text { Rate }\end{array}$ & $\begin{array}{l}\text { Recognition } \\
\text { Rate }\end{array}$ & $\begin{array}{c}\text { Overall } \\
\text { Recognition } \\
\text { Rate }\end{array}$ & $\begin{array}{l}\text { Processing } \\
\text { Time }\end{array}$ & $\begin{array}{l}\text { Real } \\
\text { Time }\end{array}$ & $\begin{array}{l}\text { Device } \\
\text { Config. }\end{array}$ & $\begin{array}{l}\text { Plate } \\
\text { Format }\end{array}$ & $\begin{array}{l}\text { Problem } \\
\text { Areas }\end{array}$ \\
\hline 1 & [39] & $\begin{array}{l}\text { Otsu } \\
\text { Adaptive } \\
\text { thresh- } \\
\text { olding, } \\
\text { CCA, } \\
\text { Edge } \\
\text { Detection- } \\
\text { Canny }\end{array}$ & $\begin{array}{l}\text { Closed } \\
\text { curves }\end{array}$ & $\begin{array}{l}\text { Template } \\
\text { Match- } \\
\text { ing }\end{array}$ & $\begin{array}{c}\text { Set 1: } 533 \\
\text { Set 2: } 651 \\
\text { Set 3: } 757 \\
\text { Set 4: } 611 \\
\text { (Video } \\
\text { Sequences) }\end{array}$ & $\begin{array}{l}\text { Various } \\
\text { situations } \\
\text { with } \\
\text { different } \\
\text { Light } \\
\text { Conditions }\end{array}$ & $\begin{array}{l}\text { Set 1: } \\
96.37 \% \\
\text { Set 2-4: } \\
96.06 \%\end{array}$ & - & $\begin{array}{l}\text { Set 1: } 98.1 \% \\
\text { Set 2: } 96.37 \% \\
\text { Set 3: } 93.07 \% \\
\text { Set 4: } 92.52 \%\end{array}$ & - & - & No & $\begin{array}{c}\text { 4GB } \\
\text { memory } \\
\text { DDR4 and } \\
3.4 \mathrm{GHz} \\
\text { Intel(R) } \\
\text { Core(TM) i5 } \\
\text { CPU - } \\
\text { MATLAB } \\
\text { R2015b }\end{array}$ & $\begin{array}{l}\text { Moroccan } \\
\text {, four } \\
\text { different } \\
\text { formats }\end{array}$ & - \\
\hline 2 & [38] & $\begin{array}{c}\text { Edge } \\
\text { statistics } \\
\text { and mor- } \\
\text { phology } \\
\text { tech- } \\
\text { niques }\end{array}$ & $\begin{array}{l}\text { Bounding } \\
\text { box }\end{array}$ & $\begin{array}{l}\text { Template } \\
\text { Match- } \\
\text { ing }\end{array}$ & 9745 images & - & $98 \%$ & - & $82.6 \%$ & $75-85 \%$ & - & No & MATLAB & Indian & $\begin{array}{l}\text { Not suitable } \\
\text { for different } \\
\text { orienta- } \\
\text { tions. }\end{array}$ \\
\hline 3 & [140] & $\begin{array}{l}\text { Used } \\
\text { provided } \\
\text { Images }\end{array}$ & - & $\begin{array}{l}\text { HOG } \\
\text { feature } \\
\text { and } \\
\text { Extreme } \\
\text { Learn- } \\
\text { ing } \\
\text { Machine }\end{array}$ & $\begin{array}{l}69 \text { images, } 45 \\
\text { images used } \\
\text { as trainers, } 5 \\
\text { classes }\end{array}$ & $\begin{array}{l}\text { Low } \\
\text { resolution } \\
\text { portion of } \\
\text { the image, } \\
\text { 15-18 px } \\
\text { height }\end{array}$ & - & - & $90 \%$ & $90 \%$ & - & Yes & - & $\begin{array}{l}\text { South } \\
\text { Thailand }\end{array}$ & $\begin{array}{l}\text { Day time } \\
\text { only, no } \\
\text { license } \\
\text { localization } \\
\text { process is } \\
\text { applied. }\end{array}$ \\
\hline 4 & [141] & $\begin{array}{l}\text { Morphology } \\
\text { Tech- } \\
\text { niques }\end{array}$ & $\begin{array}{l}\text { Region } \\
\text { props } \\
\text { bounding } \\
\text { box using } \\
\text { Matlab }\end{array}$ & $\begin{array}{l}\text { Template } \\
\text { Match- } \\
\text { ing }\end{array}$ & 30 images & $\begin{array}{l}\text { Low } \\
\text { brightness, } \\
\text { contrast }\end{array}$ & $92 \%$ & $97 \%$ & $98 \%$ & $98 \%$ & - & No & Matlab & $\begin{array}{l}\text { Multi } \\
\text { Fonts, } \\
\text { Indian }\end{array}$ & - \\
\hline
\end{tabular}


Table 2. Cont.

\begin{tabular}{|c|c|c|c|c|c|c|c|c|c|c|c|c|c|c|c|}
\hline No. & From & Extraction & $\begin{array}{l}\text { Procedure } \\
\text { Segmentation }\end{array}$ & Recognition & Database & $\begin{array}{l}\text { Image } \\
\text { Condition }\end{array}$ & $\begin{array}{l}\text { Extraction } \\
\text { Rate }\end{array}$ & $\begin{array}{l}\text { Segmentation } \\
\text { Rate }\end{array}$ & $\begin{array}{l}\text { Recognition } \\
\text { Rate }\end{array}$ & $\begin{array}{c}\text { Overall } \\
\text { Recognition } \\
\text { Rate }\end{array}$ & $\begin{array}{l}\text { Processing } \\
\text { Time }\end{array}$ & $\begin{array}{l}\text { Real } \\
\text { Time }\end{array}$ & $\begin{array}{l}\text { Device } \\
\text { Config. }\end{array}$ & $\begin{array}{l}\text { Plate } \\
\text { Format }\end{array}$ & $\begin{array}{l}\text { Problem } \\
\text { Areas }\end{array}$ \\
\hline 5 & [36] & $\begin{array}{l}\text { Histogram } \\
\text { Analysis } \\
\text { using } \\
\text { HOG }\end{array}$ & $\begin{array}{c}\text { Vertical } \\
\text { Histogram }\end{array}$ & $\begin{array}{l}\text { OCR - } \\
\text { Tem- } \\
\text { plate } \\
\text { Match- } \\
\text { ing }\end{array}$ & 110 images & $\begin{array}{l}\text { Various } \\
\text { Conditions }\end{array}$ & $89.7 \%$ & - & - & - & - & No & OpenALPR & Europe & $\begin{array}{c}\text { Cannot detect } \\
\text { beyond } \\
\text { 30-degrees } \\
\text { horizon- } \\
\text { tal/vertical } \\
\text { angle, if the } \\
\text { car is moving } \\
\text { (image blur) } \\
\text { or there is low } \\
\text { light }\end{array}$ \\
\hline 6 & [78] & $\begin{array}{l}\text { Object } \\
\text { detection, } \\
\text { CNNs- } \\
\text { (YOLO } \\
\text { Detector) }\end{array}$ & $\begin{array}{c}\text { Character } \\
\text { Segmenta- } \\
\text { tion CNNs, } \\
\text { Bounding } \\
\text { box }\end{array}$ & $\begin{array}{c}\text { Data } \\
\text { augmen- } \\
\text { tation, } \\
\text { Distant } \\
\text { CNNs } \\
\text { for letter } \\
\text { and } \\
\text { Digits }\end{array}$ & $\begin{array}{l}\text { SSIG Dataset: } \\
\text { 2000 Frames, } \\
\text { UFPR-ALPR: } \\
\text { 4500 Frames }\end{array}$ & $\begin{array}{l}1920 \times 1080 \\
\text { pixels }\end{array}$ & $\begin{array}{c}\text { SSIG: } \\
\text { 100.00\% } \\
\text { UFPR- } \\
\text { ALPR: } \\
98.33 \%\end{array}$ & $\begin{array}{l}\text { SSIG: } \\
\text { 97.75\% } \\
\text { UFPR- } \\
\text { ALPR: } \\
95.97 \%\end{array}$ & $\begin{array}{c}\text { SSIG: } 97.83 \% \\
\text { UFPR-ALPR: } \\
90.37 \%\end{array}$ & $\begin{array}{l}\text { SSIG: } 93.53 \% \\
\text { UFPR-ALPR: } \\
78.33 \%\end{array}$ & $\begin{array}{l}\text { SSIG: } \\
21.31 \mathrm{~ms}, \\
47 \text { FPS } \\
\text { UFPR- } \\
\text { ALPR: } \\
28.30 \mathrm{~ms}, \\
35 \mathrm{FPS}\end{array}$ & Yes & $\begin{array}{c}\text { NVIDIA } \\
\text { Titan XP } \\
\text { GPU }(3840 \\
\text { CUDA } \\
\text { cores and } 12 \\
\text { GB of RAM }\end{array}$ & Brazil & $\begin{array}{l}\text { Adjustments } \\
\text { have to be } \\
\text { made for other } \\
\text { than Brazilian } \\
\text { formats. } \\
\text { Dependent on } \\
\text { license plate } \\
\text { layout. }\end{array}$ \\
\hline 7 & [125] & $\begin{array}{c}\text { Cascade } \\
\text { classifier } \\
\text { with LBP } \\
\text { features } \\
\text { (Local } \\
\text { Binary } \\
\text { Pattern) }\end{array}$ & - & $\begin{array}{l}\text { Tesseract's } \\
\text { OCR }\end{array}$ & 1300 images & $\begin{array}{c}640 \times 480 \\
\text { pixels with } \\
50 \times \\
11 \text { pixels } \\
\text { aspect ratio } \\
\text { of license } \\
\text { plate, } \\
\text { various } \\
\text { conditions }\end{array}$ & $98.35 \%$ & - & $92.12 \%$ & $96.73 \%$ & $\begin{array}{l}1.2 \mathrm{~s}, 10 \\
\text { FPS }\end{array}$ & Yes & $\begin{array}{c}\text { RaspberryPi } \\
3 \text { Model B } \\
\text { operating at } \\
1.2 \mathrm{GHz} \\
\text { with } 1 \mathrm{~GB} \\
\text { RAM }\end{array}$ & Indian & $\begin{array}{c}\text { Dependent on } \\
\text { standardiza- } \\
\text { tion for } \\
\text { detection too, } \\
\text { overall } \\
\text { accuracy is for } \\
\text { front side } \\
\text { license plate } \\
\text { only at fixed } \\
90 \mathrm{~d} \text { angle, } \\
\text { High } \\
\text { processing } \\
\text { time. }\end{array}$ \\
\hline
\end{tabular}


Table 2. Cont.

\begin{tabular}{|c|c|c|c|c|c|c|c|c|c|c|c|c|c|c|c|}
\hline No. & From & Extraction & $\begin{array}{l}\text { Procedure } \\
\text { Segmentation }\end{array}$ & Recognition & Database & $\begin{array}{l}\text { Image } \\
\text { Condition }\end{array}$ & $\begin{array}{l}\text { Extraction } \\
\text { Rate }\end{array}$ & $\begin{array}{l}\text { Segmentation } \\
\text { Rate }\end{array}$ & $\begin{array}{l}\text { Recognition } \\
\text { Rate }\end{array}$ & $\begin{array}{c}\text { Overall } \\
\text { Recognition } \\
\text { Rate }\end{array}$ & $\begin{array}{l}\text { Processing } \\
\text { Time }\end{array}$ & $\begin{array}{l}\text { Real } \\
\text { Time }\end{array}$ & $\begin{array}{l}\text { Device } \\
\text { Config. }\end{array}$ & $\begin{array}{l}\text { Plate } \\
\text { Format }\end{array}$ & Problem Areas \\
\hline 8 & [117] & $\begin{array}{l}\text { LBP, } \\
\text { Charac- } \\
\text { ter and } \\
\text { edge } \\
\text { informa- } \\
\text { tion }\end{array}$ & $\begin{array}{l}\text { Vertical } \\
\text { Histogram }\end{array}$ & $\begin{array}{l}\text { Tesseract } \\
\text { OCR } \\
\text { with } \\
\text { prepro- } \\
\text { cessing } \\
\text { tech- } \\
\text { niques } \\
\end{array}$ & $1200+$ images & $\begin{array}{l}250 \text { pixels } \\
\text { wide, } \\
\text { Various } \\
\text { conditions } \\
\text { and colors }\end{array}$ & $100 \%$ & - & $90 \%$ & $90 \%$ & Vary & No & OpenALPR & Myanmar & $\begin{array}{l}\text { High } \\
\text { processing } \\
\text { time. }\end{array}$ \\
\hline 9 & [23] & $\begin{array}{l}\text { Vertical } \\
\text { and hori- } \\
\text { zontal } \\
\text { edge his- } \\
\text { tograms }\end{array}$ & $\begin{array}{c}\text { Connected } \\
\text { component } \\
\text { labeling } \\
\text { and mor- } \\
\text { phological } \\
\text { method }\end{array}$ & $\begin{array}{l}\text { Statistical } \\
\text { features } \\
\text { matched } \\
\text { with } \\
\text { stored } \\
\text { ones }\end{array}$ & 50 Images & $\begin{array}{l}\text { Variable } \\
\text { size and } \\
\text { style, Latin } \\
\text { script only }\end{array}$ & $90 \%$ & $91 \%$ & $93 \%$ & $92.75 \%$ & - & No & $\begin{array}{l}\text { MATLAB } \\
\text { R2015a }\end{array}$ & Pakistan & $\begin{array}{l}\text { Very Limited } \\
\text { dataset tested }\end{array}$ \\
\hline 10 & [26] & $\begin{array}{l}\text { Image } \\
\text { resizing } \\
\text { using } \\
\text { nearest } \\
\text { neighbor } \\
\text { interpola- } \\
\text { tion, } \\
\text { Prepro- } \\
\text { cessing } \\
\text { and geo- } \\
\text { metrical } \\
\text { condi- } \\
\text { tions }\end{array}$ & $\begin{array}{c}\text { CCA } \\
\text { labelling } \\
\text { and mor- } \\
\text { phological } \\
\text { operations }\end{array}$ & $\begin{array}{l}\text { OCR } \\
\text { algo- } \\
\text { rithms }\end{array}$ & 958 images & $\begin{array}{l}\text { HD images, } \\
\text { various } \\
\text { conditions }\end{array}$ & $98.10 \%$ & $99.75 \%$ & $99.50 \%$ & $98 \%$ & $61 \mathrm{~ms}$ & No & MATLAB & Qatar & $\begin{array}{l}\text { Computationally } \\
\text { intensive cost, } \\
\text { HD camera } \\
\text { used- } \\
\text { memory and } \\
\text { time } \\
\text { constraints }\end{array}$ \\
\hline 11 & [121] & - & $\begin{array}{l}\text { Preprocessing } \\
\text { techniques, } \\
\text { Otsu's } \\
\text { Threshold- } \\
\text { ing }\end{array}$ & $\begin{array}{l}\text { Bounding } \\
\text { box } \\
\text { feature } \\
\text { and } \\
\text { template } \\
\text { match- } \\
\text { ing } \\
\text { OCR }\end{array}$ & 14 images & $\begin{array}{c}8 \mathrm{mp} \\
\text { camera, } \\
\text { different } \\
\text { timings and } \\
\text { distances }\end{array}$ & - & - & - & $92.85 \%$ & - & No & MATLAB & Malaysia & $\begin{array}{l}\text { Limited set of } \\
\text { images, cannot } \\
\text { recognize low } \\
\text { quality images, } \\
\text { works for } \\
\text { standardized } \\
\text { format only }\end{array}$ \\
\hline
\end{tabular}


Table 2. Cont.

\begin{tabular}{|c|c|c|c|c|c|c|c|c|c|c|c|c|c|c|c|}
\hline No. & From & Extraction & $\begin{array}{l}\text { Procedure } \\
\text { Segmentation }\end{array}$ & Recognition & Database & $\begin{array}{l}\text { Image } \\
\text { Condition }\end{array}$ & $\begin{array}{c}\text { Extraction } \\
\text { Rate }\end{array}$ & $\begin{array}{c}\text { Segmentation } \\
\text { Rate }\end{array}$ & $\begin{array}{l}\text { Recognition } \\
\text { Rate }\end{array}$ & $\begin{array}{c}\text { Overall } \\
\text { Recognition } \\
\text { Rate }\end{array}$ & $\begin{array}{l}\text { Processing } \\
\text { Time }\end{array}$ & $\begin{array}{l}\text { Real } \\
\text { Time }\end{array}$ & $\begin{array}{l}\text { Device } \\
\text { Config. }\end{array}$ & $\begin{array}{l}\text { Plate } \\
\text { Format }\end{array}$ & $\begin{array}{l}\text { Problem } \\
\text { Areas }\end{array}$ \\
\hline 12 & [25] & $\begin{array}{l}\text { Geometrical } \\
\text { features } \\
\text { using } \\
\text { Mathe- } \\
\text { matical } \\
\text { Morphol- } \\
\text { ogy }\end{array}$ & - & - & $\begin{array}{l}571 \text { images, } \\
\text { multiple sets }\end{array}$ & $\begin{array}{c}\text { Complex } \\
\text { images, } \\
1792 \times \\
1312,800 \times \\
600, \text { and } \\
640 \times 480 \\
\text { pixels }\end{array}$ & - & - & - & $98.45 \%$ & $20 \mathrm{~ms}$ & No & $\begin{array}{c}\text { MATLAB } \\
2.7 \mathrm{GHz} \\
\text { core i7, } 8 \\
\text { GB of } \\
\text { RAM, } \\
\text { Python } \\
\text { Raspberry } \\
\text { Pi with } 700 \\
\text { MHz } \\
\text { processor } \\
\text { and 256 } \\
\text { MB of } \\
\text { RAM }\end{array}$ & Greek & $\begin{array}{l}\text { Higher } \\
\text { processing } \\
\text { time, cost and } \\
\text { power for } \\
\text { higher } \\
\text { resolution } \\
\text { images }\end{array}$ \\
\hline 13 & [103] & $\begin{array}{l}\text { ROI ex- } \\
\text { traction } \\
\text { using } \\
\text { intensity } \\
\text { detection } \\
\text { and } \\
\text { morpho- } \\
\text { logical } \\
\text { opera- } \\
\text { tions }\end{array}$ & $\begin{array}{l}\text { Otsu's } \\
\text { Threshold- } \\
\text { ing with } \\
\text { preprocess- } \\
\text { ing } \\
\text { techniques }\end{array}$ & $\begin{array}{l}\text { OCR } \\
\text { with } \\
\text { Correla- } \\
\text { tions } \\
\text { ap- } \\
\text { proach }\end{array}$ & 40 Images & $\begin{array}{l}480 \times 640 \\
\text { pixels }\end{array}$ & $87.5 \%$ & - & $85.7 \%$ & $86.6 \%$ & - & No & $\begin{array}{l}\text { MATLAB } \\
\text { R2014a. }\end{array}$ & Iraq & $\begin{array}{l}\text { Failed for } \\
\text { multiple } \\
\text { objects in the } \\
\text { scene and for } \\
\text { unclear } \\
\text { images or } \\
\text { algorithm } \\
\text { removing } \\
\text { objects by } \\
\text { mistake }\end{array}$ \\
\hline 14 & [142] & $\begin{array}{l}\text { Scale- } \\
\text { Adaptive } \\
\text { System, } \\
\text { Feature } \\
\text { computa- } \\
\text { tion with } \\
\text { Gentle- } \\
\text { boost } \\
\text { algo- } \\
\text { rithms }\end{array}$ & $\begin{array}{c}\text { Scale- } \\
\text { weighted } \\
\text { linear inter- } \\
\text { polation }\end{array}$ & $\begin{array}{l}\text { Scale- } \\
\text { adaptive } \\
\text { model } \\
\text { and em- } \\
\text { pirically } \\
\text { constrained- } \\
\text { deformation } \\
\text { model }\end{array}$ & $\begin{array}{l}\text { 2600+ images } \\
\text { Multiple } \\
\text { Datasets OS, } \\
\text { Stills\&Caltech, } \\
\text { AOLP }\end{array}$ & $\begin{array}{l}\text { Variable } \\
\text { Distances } \\
\text { between } \\
\text { camera } \\
\text { and } \\
\text { vehicle, } \\
\text { scenes and } \\
\text { sizes (in } \\
\text { color JPEG } \\
\text { format) }\end{array}$ & $\begin{array}{c}\text { OS: } 87.38 \% \\
\text { Stills\&Caltech: } \\
\quad 84.41 \%\end{array}$ & $\begin{array}{l}\text { OS: } 74.29 \% \\
\text { Stills\&Caltech: } \\
\quad 84.13 \%\end{array}$ & $98.98 \%$ & $97 \%$ & $3.16-9.43 \mathrm{~s}$ & Yes & $\begin{array}{c}\text { PASCAL } \\
\text { Visual } \\
\text { Object } \\
\text { Classes }\end{array}$ & $\begin{array}{l}\text { USA, } \\
\text { Taiwan, } \\
\text { Spanish }\end{array}$ & $\begin{array}{c}\text { Extensive } \\
\text { training } \\
\text { required } \\
\text { comprise all } \\
\text { the possible } \\
\text { situations, } \\
\text { Segmentation } \\
\text { process can be } \\
\text { enhanced by } \\
\text { using } \\
\text { additional } \\
\text { morphologi- } \\
\text { cal } \\
\text { techniques. }\end{array}$ \\
\hline
\end{tabular}


Table 2. Cont.

\begin{tabular}{|c|c|c|c|c|c|c|c|c|c|c|c|c|c|c|c|}
\hline No. & From & Extraction & $\begin{array}{l}\text { Procedure } \\
\text { Segmentation }\end{array}$ & Recognition & Database & $\begin{array}{l}\text { Image } \\
\text { Condition }\end{array}$ & $\begin{array}{c}\text { Extraction } \\
\text { Rate }\end{array}$ & $\begin{array}{l}\text { Segmentation } \\
\text { Rate }\end{array}$ & $\begin{array}{l}\text { Recognition } \\
\text { Rate }\end{array}$ & $\begin{array}{c}\text { Overall } \\
\text { Recognition } \\
\text { Rate }\end{array}$ & $\begin{array}{l}\text { Processing } \\
\text { Time }\end{array}$ & $\begin{array}{l}\text { Real } \\
\text { Time }\end{array}$ & $\begin{array}{l}\text { Device } \\
\text { Config. }\end{array}$ & $\begin{array}{l}\text { Plate } \\
\text { Format }\end{array}$ & $\begin{array}{l}\text { Problem } \\
\text { Areas }\end{array}$ \\
\hline 15 & [126] & $\begin{array}{l}\text { Support } \\
\text { Vector } \\
\text { Machine } \\
\text { (SVM) } \\
\text { with } \\
\text { Prepro- } \\
\text { cessing } \\
\text { tech- } \\
\text { niques }\end{array}$ & $\begin{array}{c}\text { Threshold, } \\
\text { Morpholog- } \\
\text { ical } \\
\text { operations } \\
\text { and } \\
\text { Contours } \\
\text { Algorithms }\end{array}$ & $\begin{array}{l}\text { Artificial } \\
\text { Neural } \\
\text { Net- } \\
\text { work } \\
\text { (ANN) }\end{array}$ & - & - & - & - & - & - & - & No & $\begin{array}{c}\text { Intel core } \\
\text { i5 PC, C++ } \\
\text { with } \\
\text { OPENCV } \\
3.2 .0 \\
\text { Library }\end{array}$ & Spain & - \\
\hline 16 & {$[24]$} & $\begin{array}{l}\text { Image } \\
\text { resizing, } \\
\text { Prepro- } \\
\text { cessing } \\
\text { and geo- } \\
\text { metrical } \\
\text { condi- } \\
\text { tions }\end{array}$ & $\begin{array}{c}\text { CCA } \\
\text { labelling } \\
\text { and mor- } \\
\text { phological } \\
\text { operations }\end{array}$ & $\begin{array}{l}\text { OCR } \\
\text { using } \\
\text { Field } \\
\text { Pro- } \\
\text { grammable } \\
\text { Gate } \\
\text { Array } \\
\text { (FPGA) } \\
\text { Process- } \\
\text { ing } \\
\text { Unit }\end{array}$ & $\begin{array}{c}\text { 454+ Images, } \\
2790 \\
\text { Characters }\end{array}$ & $\begin{array}{c}\text { HD images } \\
\text { with } 34 \times \\
22 \\
\text { character } \\
\text { size matrix, } \\
\text { various } \\
\text { light and } \\
\text { weather } \\
\text { conditions }\end{array}$ & - & - & - & $99.50 \%$ & $3.78 \mathrm{~ms}$ & Yes & $\begin{array}{c}\text { Matlab, } \\
\text { Xilinx } \\
\text { Zynq-7000 } \\
\text { All Pro- } \\
\text { grammable } \\
\text { SoC, } \\
\text { FPGA/ARM }\end{array}$ & Qatar & $\begin{array}{l}\text { Computationally } \\
\text { intensive cost, } \\
\text { HD camera } \\
\text { used-memory } \\
\text { and time } \\
\text { constraints }\end{array}$ \\
\hline 17 & [116] & $\begin{array}{c}\text { Region of } \\
\text { Interest } \\
\text { (ROI) } \\
\text { based } \\
\text { filtering }\end{array}$ & $\begin{array}{c}\text { Vertical } \\
\text { Edge } \\
\text { Detection } \\
\text { with } \\
\text { removal of } \\
\text { long edges }\end{array}$ & - & $1000+$ videos & $\begin{array}{l}\text { Different } \\
\text { orienta- } \\
\text { tion, light } \\
\text { conditions } \\
\text { and type of } \\
\text { vehicles }\end{array}$ & - & - & - & $92.31 \%$ & 8.3 FPS & Yes & - & Indian & $\begin{array}{c}\text { Format } \\
\text { dependent }\end{array}$ \\
\hline 18 & [103] & $\begin{array}{l}\text { Intensity } \\
\text { detection } \\
\text { and } \\
\text { mathe- } \\
\text { matical } \\
\text { morpho- } \\
\text { logical } \\
\text { opera- } \\
\text { tions }\end{array}$ & $\begin{array}{l}\text { Labeling } \\
\text { connected } \\
\text { compo- } \\
\text { nents }\end{array}$ & $\begin{array}{c}\text { Back } \\
\text { propaga- } \\
\text { tion } \\
\text { Neural } \\
\text { Net- } \\
\text { work } \\
\text { (BPNN) }\end{array}$ & 60 images & $\begin{array}{l}\text { Variable } \\
\text { size and il- } \\
\text { lumination } \\
\text { condition }\end{array}$ & $98.3 \%$ & - & $93.2 \%$ & $97.75 \%$ & - & No & $\begin{array}{l}\text { MALAB } \\
\text { R2014a }\end{array}$ & Iraq & - \\
\hline
\end{tabular}


Table 2. Cont.

\begin{tabular}{|c|c|c|c|c|c|c|c|c|c|c|c|c|c|c|c|}
\hline No. & From & Extraction & $\begin{array}{l}\text { Procedure } \\
\text { Segmentation }\end{array}$ & Recognition & Database & $\begin{array}{l}\text { Image } \\
\text { Condition }\end{array}$ & $\begin{array}{c}\text { Extraction } \\
\text { Rate }\end{array}$ & $\begin{array}{l}\text { Segmentation } \\
\text { Rate }\end{array}$ & $\begin{array}{l}\text { Recognition } \\
\text { Rate }\end{array}$ & $\begin{array}{c}\text { Overall } \\
\text { Recognition } \\
\text { Rate }\end{array}$ & $\begin{array}{l}\text { Processing } \\
\text { Time }\end{array}$ & $\begin{array}{l}\text { Real } \\
\text { Time }\end{array}$ & $\begin{array}{l}\text { Device } \\
\text { Config. }\end{array}$ & $\begin{array}{l}\text { Plate } \\
\text { Format }\end{array}$ & $\begin{array}{l}\text { Problem } \\
\text { Areas }\end{array}$ \\
\hline 19 & [19] & $\begin{array}{l}\text { Method } \\
\text { E1: } \\
\text { Vertical } \\
\text { edge } \\
\text { detection } \\
\text { using } \\
\text { Sobel filter } \\
\text { Method } \\
\text { E2: } \\
\text { Gradient } \\
\text { extraction, } \\
\text { vertical } \\
\text { his- } \\
\text { tograms, } \\
\text { CCA } \\
\text { Method } \\
\text { E3: Using } \\
\text { shape } \\
\text { features }\end{array}$ & $\begin{array}{c}\text { Pixel } \\
\text { Projection } \\
\text { in Vertical } \\
\text { and } \\
\text { Horizontal } \\
\text { directions }\end{array}$ & $\begin{array}{l}\text { OCR1: } \\
\text { Tem- } \\
\text { plate } \\
\text { Match- } \\
\text { ing } \\
\text { OCR2: } \\
\text { PNN }\end{array}$ & 141 images & $\begin{array}{c}1024 \times 768 \\
\text { pixels, } \\
\text { Variable } \\
\text { conditions }\end{array}$ & $\begin{array}{l}\text { E1: } 65.25 \% \\
\text { E2: } 43.26 \% \\
\text { E3: } 33.33 \%\end{array}$ & $\begin{array}{l}\text { E1: } 60.87 \% \\
\text { E2: } 63.93 \% \\
\text { E3: } 65.91 \%\end{array}$ & $\begin{array}{l}\text { OCR1 for } \\
\text { E1: } 81.99 \% \\
\text { E2: } 78.65 \% \text { E3: } \\
81.50 \% \text { OCR2 } \\
\text { for } \\
\text { E1: } 82.42 \% \\
\text { E2: } 78.36 \% \\
\text { E3: } 77.95 \%\end{array}$ & $\begin{array}{l}\text { OCR1 for } \\
\text { E1: } \quad 42.41 \% \\
\text { E2: } 28.12 \% \text { E3: } \\
21.66 \% \text { OCR2 } \\
\text { for } \\
\text { E1: } 42.01 \% \\
\text { E2: } 27.86 \% \\
\text { E3: } 21.46 \%\end{array}$ & - & No & - & Canada & $\begin{array}{l}\text { All methods } \\
\text { were tested as } \\
\text { from literature } \\
\text { to verify the } \\
\text { researcher's } \\
\text { claims and } \\
\text { almost all } \\
\text { failed for } \\
\text { variable } \\
\text { datasets. }\end{array}$ \\
\hline 20 & [112] & $\begin{array}{c}\text { Pixel } \\
\text { Statistics } \\
\text { with pre- } \\
\text { processing } \\
\text { tech- } \\
\text { niques }\end{array}$ & $\begin{array}{l}\text { RGB Color } \\
\text { Extractor } \\
\text { and } \\
\text { character } \\
\text { isolation } \\
\text { using } \\
\text { threshold- } \\
\text { ing. }\end{array}$ & $\begin{array}{l}\text { Template } \\
\text { Match- } \\
\text { ing }\end{array}$ & 255 Images & $\begin{array}{c}\text { Color } \\
\text { Images, } \\
2448 * 3264 \\
* 80 \text { pixels } \\
\text { Camera: } \\
\text { iPhone 5s } \\
\text { (Variable } \\
\text { light } \\
\text { conditions) }\end{array}$ & - & $98.5 \%$ & $95.1 \%$ & $95 \%$ & - & Yes & $\begin{array}{l}\text { Tesseract- } \\
\text { Open- } \\
\text { source } \\
\text { OCR } \\
\text { engine }\end{array}$ & $\begin{array}{c}\text { United } \\
\text { States } \\
\text { (Illi- } \\
\text { nois) }\end{array}$ & $\begin{array}{c}\text { Format } \\
\text { specific. Not } \\
\text { compatible } \\
\text { with low light } \\
\text { images. } \\
\text { Ambiguous } \\
\text { characters } \\
\text { have low } \\
\text { recognition }\end{array}$ \\
\hline
\end{tabular}


Table 2. Cont

\begin{tabular}{|c|c|c|c|c|c|c|c|c|c|c|c|c|c|c|c|}
\hline No. & From & & Procedure & & Database & $\begin{array}{c}\text { Image } \\
\text { Condition }\end{array}$ & $\begin{array}{l}\text { Extraction } \\
\text { Rate }\end{array}$ & $\begin{array}{l}\text { Segmentation } \\
\text { Rate }\end{array}$ & $\begin{array}{c}\text { Recognition } \\
\text { Rate }\end{array}$ & $\begin{array}{c}\text { Overall } \\
\text { Recognition } \\
\text { Rate }\end{array}$ & $\begin{array}{l}\text { Processing } \\
\text { Time }\end{array}$ & $\begin{array}{l}\text { Real } \\
\text { Time }\end{array}$ & $\begin{array}{l}\text { Device } \\
\text { Config. }\end{array}$ & $\begin{array}{c}\text { Plate } \\
\text { Format }\end{array}$ & Problem Areas \\
\hline & & Extraction & Segmentation & Recognition & & & & & & & & & & & \\
\hline 21 & [143] & $\begin{array}{l}\text { Filtering } \\
\text { techniques } \\
\text { with } \\
\text { contrast en- } \\
\text { hancement } \\
\text { and other } \\
\text { preprocess- } \\
\text { ing } \\
\text { techniques }\end{array}$ & $\begin{array}{l}\text { Vertical } \\
\text { Projection } \\
\text { method }\end{array}$ & $\begin{array}{l}\text { OCR } \\
\text { using } \\
\text { ANN }\end{array}$ & - & $\begin{array}{l}\text { Color } \\
\text { Images } \\
\text { taken with } \\
5 \text { MP phone } \\
\text { built-in } \\
\text { Camera, } \\
1600 * 1200 \\
\text { pixels }\end{array}$ & - & $83.5 \%$ & $92 \%$ & $88 \%$ & - & Yes & $\begin{array}{c}\text { Eclipse IDE, } \\
\text { Android } \\
\text { Platform } \\
\text { SDK } \\
\text { Processor: } \\
\text { ARM v6 } \\
\text { 800MHz } \\
\text { RAM: } 285 \\
\text { Mega Bytes } \\
\text { Screen Size: } \\
320 \times 480 \\
\text { Camera: } 5 \\
\text { Mega Pixels } \\
\text { OS Version: } \\
\text { 2.3 Ginger } \\
\text { Bread }\end{array}$ & Malaysia & $\begin{array}{c}\text { Low resolution } \\
\text { camera, Format } \\
\text { specific, Limited } \\
\text { system memory, } \\
\text { Motion blur, } \\
\text { object } \\
\text { obscuring, } \\
\text { day/night shots } \\
\text { are problem } \\
\text { areas for the } \\
\text { system. It can } \\
\text { be improved a } \\
\text { lot in future. }\end{array}$ \\
\hline 22 & [144] & $\begin{array}{l}\text { Color } \\
\text { features } \\
\text { (Hue and } \\
\text { shape) with } \\
\text { verti- } \\
\text { cal/slope } \\
\text { sweep }\end{array}$ & $\begin{array}{c}\text { Image } \\
\text { Processing } \\
\text { Filter } \\
\text { (Histogram, } \\
\text { Laplacian, } \\
\text { Morphology), } \\
\text { Connected } \\
\text { Compo- } \\
\text { nent/Projection } \\
\text { Analysis }\end{array}$ & $\begin{array}{l}\text { Decision } \\
\text { Tree and } \\
\text { SVM }\end{array}$ & $\begin{array}{l}\text { Set1: } 1150 \mathrm{Im}- \\
\text { ages } \\
\text { Set2: } 540 \\
\text { Images }\end{array}$ & $\begin{array}{l}\text { Set1: Gatso } \\
\text { control } \\
\text { speed } \\
\text { cameras on } \\
\text { highways } \\
\text { Set2: Parked } \\
\text { Vehicles } \\
\text { captured } \\
\text { with phone } \\
\text { camera } \\
1.3 \mathrm{MP} . \\
\text { (Different } \\
\text { conditions) }\end{array}$ & $\begin{array}{c}\text { Set1: Speed } \\
\text { Lane: } 96.6 \% \\
\text { Mid Lane: } \\
\text { 93.14\% Side } \\
\text { Lane: } 78.8 \% \\
\text { Multi } \\
\text { Vehicles: } 96 \% \\
\text { Set2: Day: } \\
\text { 96.8\% Night: } \\
\text { 91.4\% } \\
\text { Angled upto } \\
20^{\circ}: 74.6 \%\end{array}$ & - & - & $\begin{array}{c}\text { Speed Lane: } \\
\text { 92.6\% Mid } \\
\text { Lane: } 87.14 \% \\
\text { Side Lane: } \\
64.8 \% \text { Multi } \\
\text { Vehicles: } 94 \% \\
\text { Set2: Day: } \\
\text { 94.4\% Night: } \\
\text { 72.14\% Angled } \\
\text { upto } 20^{\circ}: 62 \%\end{array}$ & $\begin{array}{l}0.75-1.59 \mathrm{~s} \\
\quad \text { (Total } \\
\text { system } \\
\text { response) }\end{array}$ & Yes & $\begin{array}{l}1.7 \mathrm{GHz} \\
\text { CPU with } 4 \\
\text { GB RAM }\end{array}$ & Iran & $\begin{array}{c}\text { Practical and } \\
\text { accurate for } \\
\text { targeted lane. } \\
\text { The claimed } \\
96 \%, 94 \% \\
\text { system } \\
\text { performance is } \\
\text { tested on a very } \\
\text { limited data set. } \\
\text { The overall } \\
\text { performance } \\
\text { considering } \\
\text { other lanes is } \\
\text { comparatively } \\
\text { poor in } \\
\text { recognition for } \\
\text { set1. In set2, } \\
\text { only daylight } \\
\text { images are well } \\
\text { recognized with } \\
\text { poor results } \\
\text { otherwise. }\end{array}$ \\
\hline
\end{tabular}


Table 2 presents the performance summary of various algorithms applied by researchers in the ANPR field, for different stages involved. Since this a multi stage/step algorithms, the only common parameter is the success rate/overall performance at each individual stage. The stages involved are shown in Figure 2. All the parameters in Table 2 heading were kept common for evaluating different approaches from researchers. The techniques listed from different researches under these header parameters is uncommon since this technology has no common algorithm to follow and it totally depends on the researchers that they mix and match various available algorithms and techniques to create their proposed recognition model for ANPR systems. The general input in such systems as given is the vehicle visual/image and is given as "datasets", while output to the system is given as percentage of "overall recognition rate" that is the successfully recognized vehicle number plates in form of text string. This recognized data is then used for required post processing operations. Some of these stages use ML techniques. Since there is no uniform procedure available for ANPR systems for a side-by-side comparison, we have analyzed and summarized different algorithms that worked best with a variation of techniques applied. It is worth mentioning that the performance parameters we considered were constant for all, as shown in the table. We studied the procedures for all the studies/works presented in the Table 2; these included the general steps of number plate extraction, segmentation and recognition, and their success rates. Other factors considered for comparison are database size, image conditions, number plate formats, processing time, recognition rate, the device configuration for carrying out the test either in real time or on pre-acquired number plate images sets. The potential issues or problem areas, where identified by the researchers, are also discussed. From this analysis, we can conclude that the algorithms presented for the real time systems showed great overall accuracy rate, which is very impressive. However, uniform evaluation of different algorithms has requirements as indicated towards the end of the Conclusion Section.

In [24], 99.5\% accuracy rate is achieved by using HD cameras for over 2790 characters tested in real time. CCA with OCR algorithms were used for Qatar number plates format. However, it is clearly computationally intensive, and involves high system cost with memory and processing time constraints. In [78], the number plate extraction rate is $98.33 \%$ to $100 \%$ for different datasets tested in real time scenarios for Brazilian number plates. The overall recognition efficiency is $93.53 \%$ (dataset SSIG) and 78.33\% (UFPR-ALPR). The authors here applied the CNN based algorithms and YOLO object detector. In [142], scale adaptive model is tested for real time scenarios with an overall success rate of $97 \%$ by applying it to over $2600 \mathrm{mix}$ format number plates. However, the process required extensive model training to cover varying situations. The Local Binary pattern extraction with Tesseract's OCR is applied in [125] for real time scenarios with tested dataset of about 1300 images. The overall accuracy is $96.73 \%$ is impressive but the fact that the authors only considered fixed angles for image acquisition and hence there is still room to research different angles with same algorithms applied.

A rough number plate condition may affect the process of recognition and the environmental conditions makes it even more challenging. Current ANPR systems use low resolution camera most of the times to keep the system cost lower and hence the video quality in real time has enough probability to make errors. HD cameras can be used to solve this issue as these cameras have the capacity to capture fine details from even long ranges. ANPR accuracy can be improved considerably if the camera is correctly setup by keeping the distance, tilt angles, region of interest zooming and lighting factors in consideration. Depending on the environment and camera shutter speed, the processing capabilities vary. In [26], HD cameras are employed. The recognition rate of $98 \%$ is achieved. In [24], the recognition rate of similar system is $99.5 \%$. However, systems with HD cameras are computationally expensive, involve higher cost, greater memory requirements and also have processing time constraints. Some studies involved the use of classifiers for the recognition purpose. They are either using a combination of multiple classifiers in parallel or have multistage classification schemes. Artificial Neural Network 
is used in [126]. Convolutional Neural Networks is used in [78] in real time scenario and has shown great results for each stage of ANPR system. Neural network based algorithms seems promising for ANPR and are proposed in [19,103,145-162].

In [163], an alternative but unique self-learning algorithm, based on Bayesian-probability and Levenshtein-Text-Mining, is proposed. It offers higher matching accuracy of ANPR system. It utilizes conditional probabilities of observing one character at a station for an assigned character at some other station, using the "Association Matrix".

Tesseract is the most widely adopted OCR engine, with the ability to recognize over 100 languages and is not limited to further training of new/unlisted languages. Majority of the AI/ML based ANPR software providers utilize this engine for vehicle recognition applications. There are many vendors providing ANPR solutions around the globe. For example, the OpenALPR specializes in license plate and vehicle recognition software. It is an open-source license plate reader service provider and is available as commercial software too. The most convenient feature is the compatibility with most cameras and diverse environmental conditions. Since this is based on artificial intelligence and machine vision technology, its success is solely based on the effectiveness of the algorithms used in the software along the hardware employed in the ANPR system.

Public and commercial vehicle image-datasets are available for testing ANPR algorithms and some of these are listed in Table 3. These datasets are of great help to the research community and are widely utilized with attributions to the providing source. Researchers can use these images for testing the accuracy of their algorithms. These datasets comprise of a great number of real-time images captured under diverse conditions. These images/videos have variations in backgrounds, lighting conditions, environmental conditions, plate position, physical conditions, size, style format and possible real time effecting metrics. Some of them have both open-source and commercial versions available; the latter normally using different algorithms for OCR, based on larger datasets, to offer higher accuracy than the former.

Table 3. ANPR Datasets available to the research community.

\begin{tabular}{|c|c|c|c|}
\hline Source/API & Datasets & Size $(1 \mathrm{k}=1000)$ & Version and Availability $^{2}$ \\
\hline [79] & Sighthound & Over 3 million images & $\begin{array}{l}\text { Open source Commercial Publicly available } \\
\text { to the research community }\end{array}$ \\
\hline [164] & ImageNet & Over 14 million images & Publicly Available \\
\hline$[78]$ & UFPR-ALPR & $4.5 \mathrm{k}$ images & $\begin{array}{l}\text { Non-commercial use only Available on } \\
\text { request for academic purposes }\end{array}$ \\
\hline [165] & $\begin{array}{c}\text { CompCars } \\
\text { CCPD: Chinese }\end{array}$ & $136.7 \mathrm{k}$ images & Non-commercial Research purposes only \\
\hline [166] & $\begin{array}{l}\text { City Parking } \\
\text { Dataset }\end{array}$ & $250 \mathrm{k}$ unique images & Open source under MIT license \\
\hline [167] & $\begin{array}{l}\text { VMMR: Vehicle } \\
\text { Make and Model } \\
\text { Recognition }\end{array}$ & $291.7 \mathrm{k}$ images & $\begin{array}{c}\text { Publicly available to the research community } \\
\text { Latest versions of dataset can be provided } \\
\text { upon request }\end{array}$ \\
\hline [168] & SSIG-SegPlate & $6.6 \mathrm{k}$ images & Available on request only \\
\hline [169] & $\begin{array}{l}\text { AOLP: Application- } \\
\text { Oriented License } \\
\text { Plate Recognition }\end{array}$ & $2 \mathrm{k}$ images & $\begin{array}{l}\text { Available on request for research purposes } \\
\text { only }\end{array}$ \\
\hline [170] & $\begin{array}{l}\text { Cars Dataset by } \\
\text { Stanford }\end{array}$ & $16.1 \mathrm{k}$ Images & Publicly available for research purpose only \\
\hline [171] & Cityscapes Dataset & 25 k Images & Non-commercial Research purposes only \\
\hline [172] & Caltech & $1.5 \mathrm{k}$ images & Available with attributions \\
\hline [173] & $\begin{array}{l}\text { GTI: Grupo de } \\
\text { Tratamiento de } \\
\quad \text { Imágenes }\end{array}$ & $\begin{array}{l}3.4 \mathrm{k} \text { with vehicles while } \\
3.9 \mathrm{k} \text { without vehicles in } \\
\text { scene, } 4000 \text { from other } \\
\text { sources }\end{array}$ & Publicly Available \\
\hline
\end{tabular}

There are quite many vendors serving the ANPR solutions systems but not all of them provide the same services and user feasibility with relative concerns. Selecting the right software is the key to getting the required accuracy in the recognition process and 
avoiding unwanted circumstances of incorrect identification of the number plate or no recognition at all due to scene complexity or ineffective algorithms used. To choose the better performing ANPR system, one must evaluate the software providers based on the criteria of pricing, working environment, developer support from the vendor, free trials and data accuracy tests.

\section{Conclusions and Future Research}

This paper presents a detailed survey on ANPR algorithms proposed and experimented in recent relevant studies. We categorized these algorithms according to the features required in recognition process at individual stages. Each stage is presented in detail for performance summary along with issues and challenges, where applicable. However, it is difficult to have a uniform evaluation and comparison if the dataset is not common, as explained later.

ANPR systems are based on complicated optical, computing and digitizing capabilities that may result in a slow recognition process of plates. The ANPR solutions available in the market do not offer a standardized set for all the countries; each company has to be provided with a well optimized system for different parts/regions of the world, since the same system as developed is not sufficient and needs to be designed according to the region where deployed; keeping all the affecting factors in considerations. OCR engines often are optimized for specific countries. It needs to be made sure if the required countries are supported in the library or engine that is installed on the camera. Each ANPR solutions system provided by vendors has its own strengths and weaknesses. The best among these is the one that caters for the needs of the region in identified system effecting conditions of that area.

Future research in ANPR still faces several challenges; For instance, there is a need to concentrate on more robust algorithms for non-standardized formats, irrespective of regions. Also, all proposed/designed algorithms need to be tested for real time scenarios rather pre-acquired images. In addition, high resolution cameras need to be integrated, allowing robust algorithms to reduce processing times and increase recognition capabilities. Yet another avenue is Obscure character recognition, since there are a lot similarities in characters like the pairs- $(\mathrm{O}, 0),(\mathrm{P}, \mathrm{B}),(\mathrm{Z}, 2),(\mathrm{S}, 5),(3,8),(\mathrm{B}, 8),(\mathrm{P}, \mathrm{R}),(\mathrm{D}, \mathrm{O}),(1, \mathrm{I}),(\mathrm{Q}, \mathrm{O}),(\mathrm{C}, \mathrm{G})$, $(\mathrm{A}, 4),(\mathrm{K}, \mathrm{X}),(\mathrm{F}, \mathrm{E}),(\mathrm{b}, 6),(\mathrm{q}, 9),(\mathrm{p}, \mathrm{b}),(\mathrm{V}, \mathrm{W}),(\mathrm{X}, \mathrm{Y}),(\mathrm{V}, \mathrm{U}),(6,8),(5,3),(5,8),(0,8),(3,9),(4,9)$ etc. The similarities, together with impairments, can easily deceive the optical character recognition mechanism if there is small tilt, fonts change, broken, snow or dirt on characters or if the image is acquired at different angles. Lastly, it is recommended that moving vehicles, fast speeds, low contrast, insufficient or over exposed lights and real time scenarios must be tested to check robustness of the proposed algorithms.

With recent advancements in Deep learning, Computer vision systems are enabling numerous exciting applications, ranging from safe autonomous driving to accurate object recognition, to automatic reading of images in various applications [174]. Other real time object detectors such as YOLO, can be trained and evaluated for this system [175].

Android platform has gained much importance in the technology field and numerous applications are being integrated with it. Many researchers have proposed the ANPR systems built on android platforms. However, their performance is very limited and have several constraints that can be worked on in future to develop a comparatively accurate phone-based recognition system for vehicles. Future concerns are memory resources, use of Global Positioning System coordinates for geo-tagging and online databases for respective applications [143].

Other than image processing based ANPR systems, RFID based vehicle verification systems are also emerging and being used in many countries for transportation applications. Radio Frequency Identification based vehicle recognition is another way to recognize vehicles identity or track them. Its purpose on road applications is similar to image processing based ANPR recognition system but the working terminology is different. RFID technology is proven to provide an effective solution to different tracking and localization 
problems that are more common in Image processing based systems. The most important step involved in recognition within CS/ML based ANPR systems is the extraction of number plate from the scene, which is most complex part in terms of performance. While using RFID for extraction/identification purposes, in case of missed vehicles this technology may come in action hence helping the ANPR. Also, the speed detection can be performed with RFIDs techniques. The vehicle may be tracked with RFID technology irrespective of its location whether is it within or without line of sight to the camera. The vehicle can be easily tracked throughout its travel on the road depending upon the types of RFID technology utilized. RFID allows toll payments facility as well. In short, RFID works on radio frequency whereas the image processing based ANPR systems are dependent on camera. RFID does not require any camera and it can communicate with the tag on the vehicle on the go, eliminating many complexities that are associated with camera dependent technologies.

Image processing based ANPR integration with RFID technology may help in various road applications and may improve system efficiency as in [176,177]. The integration of RFID and ANPR may result in a hybrid system and it can be considered for multiple applications of intelligent transport systems in present and future [176].

It is important to mention RFID technology here as future technology since many countries are now considering the integration of ANPR and RFID to take maximum benefit of the hybrid solution making the transportation system more accurate and secure. Both systems have their strengths and weaknesses. For ANPR, in terms of algorithms and performance, the main weakness is the successful localization of the vehicle number plate which is very much dependent on the camera and many other factors that makes it challenging to successfully recognize a vehicle number plate in some conditions mentioned earlier. Also, no additional transponders or tags are required to attach on the vehicles. The strength of this technology is that along with the recognition of vehicle its very helpful for security/surveillance applications since it captures the vehicles visuals.

The strength of RFID is the highest accuracy rates for recognition since it works on radio frequency detections by sensing the transponder attached on the vehicle, in most cases a label or tag. It can track the vehicle throughout the travel irrespective of the line of light as compared to the cameras based systems. It can effectively be used in etoll collection and the tag data can be updated accordingly. The weaknesses to this technology is limited in case of recognition/reading vehicle however it does not store any visuals of the scene. Detection accuracy from RFID and visual security sense from ANPR together creates a hybrid system which can make the transportation system more secure and accurate.

This technology is unfortunately not a one-size-fits-all solution and needs optimization from region-to-region. To allow a uniform evaluation of different approaches, the proposed algorithms needs to be tested using complex datasets provided various factors as diversity in number plate styles, colors, fonts, sizes, orientations/tilt/skewed, occlusions, obscure characters and other physical conditions, camera resolution, shutter speed, lightening/illumination aids, coverage capability for number plate extraction from the real time complex scenes, fast moving vehicles and to maintain low processing times and increase recognition capabilities in real time scenarios. A real-time video scene is recommended for the tests rather than using pre-taken still images.

The current state of the art approaches are more inclined towards the use of OCR engines equipped with AI capabilities. Recognition algorithms based on Artificial Neural Networks are providing better recognition rates. Integration of the ANPR system with other ICT tools is also gaining popularity such as integration of ANPR engines with GPS, Online databases, Android/IOS platforms, RFID and other various tools that serves different applications in intelligent transportation systems. Future research is needed to highlight importance and ways of incorporating this technology with other ICT tools which can be beneficial for the transport system and its policy making. The available CV algorithm's accuracy is limited to particular regions and its standardization for the number 
plates. Further research is needed to make the algorithms smart enough to work in variable environments provided non-standardized diverse number-plate datasets.

Now that the accuracy of ANPR systems is improving with time and are being used in tandem with AI capabilities and IoT, it is expected that these disruptive technologies and applications will be more widely adopted and that new use cases will emerge in the coming times. It is possible with the relevant tools/software to transform the raw augmented ANPR camera data into practical knowledge and help understand the traffic flow including passenger and freight mobility. ANPR cameras, have the potential and can be augmented with vehicle category information [178].

Author Contributions: Conceptualization, Methodology and writing of the paper was done by L. and N.M. Formal Analysis Validation and review was carried out by N.M. and S.A.A.S. The whole study was supervised by N.M., S.A.A.S facilitated the study by discussion and giving valuable suggestions for the refinement of the study. All authors have read and agreed to the published version of the manuscript.

Funding: This research received no external funding.

Institutional Review Board Statement: Not applicable.

Informed Consent Statement: Not applicable.

Data Availability Statement: Not applicable.

Conflicts of Interest: The authors declare no conflict of interest.

\section{References}

1. Luo, X.; Ma, D.; Jin, S.; Gong, Y.; Wang, D. Queue length estimation for signalized intersections using license plate recognition data. IEEE Intell. Transp. Syst. Mag. 2019, 11, 209-220. [CrossRef]

2. Lin, H.Y.; Dai, J.M.; Wu, L.T.; Chen, L.Q. A vision-based driver assistance system with forward collision and overtaking detection. Sensors 2020, 20, 5139. [CrossRef] [PubMed]

3. Thangallapally, S.K.; Maripeddi, R.; Banoth, V.K.; Naveen, C.; Satpute, V.R. E-Security System for Vehicle Number Tracking at Parking Lot (Application for VNIT Gate Security). In Proceedings of the 2018 IEEE International Students' Conference on Electrical, Electronics and Computer Science (SCEECS), Bhopal, India, 24-25 February 2018; pp. 1-4.

4. Negassi, I.T.; Araya, G.G.; Awawdeh, M.; Faisal, T. Smart Car plate Recognition System. In Proceedings of the 20181 st International Conference on Advanced Research in Engineering Sciences (ARES), Dubai, United Arab Emirates, 15 June 2018 ; pp. $1-5$.

5. Kanteti, D.; Srikar, D.; Ramesh, T. Intelligent smart parking algorithm. In Proceedings of the 2017 International Conference on Smart Technologies For Smart Nation (SmartTechCon), Bengaluru, India, 17-19 August 2017 ; pp. $1018-1022$.

6. Shreyas, R.; Kumar, B.P.; Adithya, H.; Padmaja, B.; Sunil, M. Dynamic traffic rule violation monitoring system using automatic number plate recognition with SMS feedback. In Proceedings of the 2017 2nd International Conference on Telecommunication and Networks (TEL-NET), Noida, India, 10-11 August 2017; pp. 1-5.

7. Chaithra, B.; Karthik, K.; Ramkishore, D.; Sandeep, R. Monitoring Traffic Signal Violations using ANPR and GSM. In Proceedings of the 2017 International Conference on Current Trends in Computer, Electrical, Electronics and Communication (CTCEEC), Mysore, India, 8-9 September 2017; pp. 341-346.

8. Felix, A.Y.; Jesudoss, A.; Mayan, J.A. Entry and exit monitoring using license plate recognition. In Proceedings of the 2017 IEEE International Conference on Smart Technologies and Management for Computing, Communication, Controls, Energy and Materials (ICSTM), Chennai, India, 2-4 August 2017; pp. 227-231.

9. Du, S.; Ibrahim, M.; Shehata, M.; Badawy, W. Automatic license plate recognition (ALPR): A state-of-the-art review. IEEE Trans. Circuits Syst. Video Technol. 2012, 23, 311-325. [CrossRef]

10. Birgillito, G.; Rindone, C.; Vitetta, A. Passenger mobility in a discontinuous space: Modelling access/egress to maritime barrier in a case study. J. Adv. Transp. 2018, 2018, 6518329. [CrossRef]

11. Alonso, B.; Pòrtilla, Á.I.; Musolino, G.; Rindone, C.; Vitetta, A. Network Fundamental Diagram (NFD) and traffic signal control: First empirical evidences from the city of Santander. Transp. Res. Procedia 2017, 27, 27-34. [CrossRef]

12. Croce, A.I.; Musolino, G.; Rindone, C.; Vitetta, A. Route and Path Choices of Freight Vehicles: A Case Study with Floating Car Data. Sustainability 2020, 12, 8557. [CrossRef]

13. Nuzzolo, A.; Comi, A.; Papa, E.; Polimeni, A. Understanding taxi travel demand patterns through Floating Car Data. In Proceedings of the 4th Conference on Sustainable Urban Mobility; Springer: Skiathos Island, Greece, 24-25 May 2018; pp. 445-452.

14. PlateRecognizer. Plate Recognizer ALPR. Available online: https:/ / platerecognizer.com/ (accessed on 25 November 2020 ).

15. ParkPow. a division of ParkPow. Available online: https://parkpow.com/ (accessed on 25 November 2020). 
16. Kyaw, N.N.; Sinha, G.; Mon, K.L. License plate recognition of Myanmar vehicle number plates a critical review. In Proceedings of the 2018 IEEE 7th Global Conference on Consumer Electronics (GCCE), Nara, Japan, 9-12 October 2018; pp. 771-774.

17. Chou, J.S.; Liu, C.H. Automated Sensing System for Real-Time Recognition of Trucks in River Dredging Areas Using Computer Vision and Convolutional Deep Learning. Sensors 2021, 21, 555. [CrossRef]

18. Bakhtan, M.A.H.; Abdullah, M.; Abd Rahman, A. A review on license plate recognition system algorithms. In Proceedings of the 2016 International Conference on Information and Communication Technology (ICICTM), Kuala Lumpur, Malaysia, 16-17 May 2016; pp. 84-89.

19. Ahmad, I.S.; Boufama, B.; Habashi, P.; Anderson, W.; Elamsy, T. Automatic license plate recognition: A comparative study. In Proceedings of the 2015 IEEE International Symposium on Signal Processing and Information Technology (ISSPIT), Abu Dhabi, United Arab Emirates, 7-10 December 2015; pp. 635-640. [CrossRef]

20. Zheng, D.; Zhao, Y.; Wang, J. An efficient method of license plate location. Pattern Recognit. Lett. 2005, 26, 2431-2438. [CrossRef]

21. Ashourian, M.; DaneshmandPour, N.; SHARIFI, T.O.; Moallemb, P. Real time implementation of a license plate location recognition system based on adaptive morphology. Int. J. Eng. 2013, 26, 1347-1356. [CrossRef]

22. Hongliang, B.; Changping, L. A hybrid license plate extraction method based on edge statistics and morphology. In Proceedings of the 17th International Conference on Pattern Recognition, Cambridge, UK, 26 August 2004; Volume 2, pp. 831-834.

23. Haider, S.A.; Khurshid, K. An implementable system for detection and recognition of license plates in Pakistan. In Proceedings of the 2017 International Conference on Innovations in Electrical Engineering and Computational Technologies (ICIEECT), Karachi, Pakistan, 5-7 April 2017; pp. 1-5.

24. Farhat, A.A.; Al-Zawqari, A.; Hommos, O.; Al-Qahtani, A.; Bensaali, F.; Amira, A.; Zhai, X. OCR-based hardware implementation for qatari number plate on the Zynq SoC. In Proceedings of the 2017 9th IEEE-GCC Conference and Exhibition (GCCCE), Manama, Bahrain, 8-11 May 2017; pp. 1-9.

25. Yepez, J.; Ko, S.B. Improved license plate localisation algorithm based on morphological operations. IET Intell. Transp. Syst. 2018, 12, 542-549. [CrossRef]

26. Hommos, O.; Al-Qahtani, A.; Farhat, A.; Al-Zawqari, A.; Bensaali, F.; Amira, A.; Zhai, X. HD Qatari ANPR system. In Proceedings of the 2016 International Conference on Industrial Informatics and Computer Systems (CIICS), Sharjah, United Arab Emirates, 13-15 March 2016; pp. 1-5.

27. Kanayama, K.; Fujikawa, Y.; Fujimoto, K.; Horino, M. Development of vehicle-license number recognition system using realtime image processing and its application to travel-time measurement. In Proceedings of the 41st IEEE Vehicular Technology Conference, St. Louis, MO, USA, 19-22 May 1991; pp. 798-804.

28. Busch, C.; Domer, R.; Freytag, C.; Ziegler, H. Feature based recognition of traffic video streams for online route tracing. In Proceedings of the 48th IEEE Vehicular Technology Conference. Pathway to Global Wireless Revolution (Cat. No. 98CH36151), Ottawa, ON, Canada, 21 May 1998; Volume 3, pp. 1790-1794.

29. Khan, M.; Mufti, N.; others. Comparison of various edge detection filters for ANPR. In Proceedings of the 2016 Sixth International Conference on Innovative Computing Technology (INTECH), Dublin, Ireland, 24-26 August 2016; pp. $306-309$.

30. Pechiammal, B.; Renjith, J.A. An efficient approach for automatic license plate recognition system. 2017 Third International Conference on Science Technology Engineering \& Management (ICONSTEM). IEEE, Chennai, India, 23-24 March 2017, pp. 121-129.

31. Sarfraz, M.; Ahmed, M.J.; Ghazi, S.A. Saudi Arabian license plate recognition system. In Proceedings of the 2003 International Conference on Geometric Modeling and Graphics, London, UK, 16-18 July 2003; pp. 36-41.

32. Dev, A. A novel approach for car license plate detection based on vertical edges. In Proceedings of the 2015 Fifth International Conference on Advances in Computing and Communications (ICACC), Kochi, India, 2-4 September 2015; pp. 391-394.

33. Wang, S.Z.; Lee, H.J. Detection and recognition of license plate characters with different appearances. In Proceedings of the 2003 IEEE International Conference on Intelligent Transportation Systems, Shanghai, China, 12-15 October 2003; Volume 2, pp. 979-984.

34. Lee, H.J.; Chen, S.Y.; Wang, S.Z. Extraction and recognition of license plates of motorcycles and vehicles on highways. In Proceedings of the 17th International Conference on Pattern Recognition, Cambridge, UK, 26 August 2004; Volume 4, pp. 356-359.

35. Huang, Y.P.; Chen, C.H.; Chang, Y.T.; Sandnes, F.E. An intelligent strategy for checking the annual inspection status of motorcycles based on license plate recognition. Expert Syst. Appl. 2009, 36, 9260-9267. [CrossRef]

36. Sferle, R.M.; Moisi, E.V. Automatic Number Plate Recognition for a Smart Service Auto. In Proceedings of the 2019 15th International Conference on Engineering of Modern Electric Systems (EMES), Oradea, Romania, 13-14 June 2019; pp. 57-60.

37. Kim, D.S.; Chien, S.I. Automatic car license plate extraction using modified generalized symmetry transform and image warping. In Proceedings of the 2001 IEEE International Symposium on Industrial Electronics Proceedings (Cat. No. 01TH8570), Pusan, Korea (South), 12-16 June 2001; Volume 3, pp. 2022-2027.

38. Kashyap, A.; Suresh, B.; Patil, A.; Sharma, S.; Jaiswal, A. Automatic number plate recognition. In Proceedings of the Communication Control and Networking (ICACCCN), Greater Noida, India, 12-13 October 2018; pp. 838-843.

39. Slimani, I.; Zaarane, A.; Hamdoun, A.; Atouf, I. Vehicle License Plate Localization and Recognition System for Intelligent Transportation Applications. In Proceedings of the 2019 6th International Conference on Control, Decision and Information Technologies (CoDIT), Paris, France, 23-26 April 2019; pp. 1592-1597. 
40. Anagnostopoulos, C.N.E.; Anagnostopoulos, I.E.; Psoroulas, I.D.; Loumos, V.; Kayafas, E. License plate recognition from still images and video sequences: A survey. IEEE Trans. Intell. Transp. Syst. 2008, 9, 377-391. [CrossRef]

41. Wu, B.F.; Lin, S.P.; Chiu, C.C. Extracting characters from real vehicle licence plates out-of-doors. IET Comput. Vis. 2007, 1, 2-10. [CrossRef]

42. Bellas, N.; Chai, S.M.; Dwyer, M.; Linzmeier, D. FPGA implementation of a license plate recognition SoC using automatically generated streaming accelerators. In Proceedings of the 20th IEEE International Parallel \& Distributed Processing Symposium, Rhodes, Greece, 25-29 April 2006; p. 8.

43. Wu, H.H.P.; Chen, H.H.; Wu, R.J.; Shen, D.F. License plate extraction in low resolution video. In Proceedings of the 18th International Conference on Pattern Recognition (ICPR'06), Hong Kong, China, 20-24 August 2006; Volume 1, pp. 824-827.

44. Chacon, M.I.; Zimmerman, A. License plate location based on a dynamic PCNN scheme. Proc. Int. Jt. Conf. Neural Netw 2003, 2, 1195-1200.

45. Miyamoto, K.; Nagano, K.; Tamagawa, M.; Fujita, I.; Yamamoto, M. Vehicle license-plate recognition by image analysis. In Proceedings of the IECON'91: 1991 International Conference on Industrial Electronics, Control and Instrumentation, Kobe, Japan, 28 October 1991; pp. 1734-1738.

46. Shi, X.; Zhao, W.; Shen, Y. Automatic license plate recognition system based on color image processing. In International Conference on Computational Science and Its Applications; Springer: Singapore, 9-12 May 2005; pp. 1159-1168.

47. Chang, S.L.; Chen, L.S.; Chung, Y.C.; Chen, S.W. Automatic license plate recognition. IEEE Trans. Intell. Transp. Syst. 2004, 5, 42-53. [CrossRef]

48. Lee, E.R.; Kim, P.K.; Kim, H.J. Automatic recognition of a car license plate using color image processing. In Proceedings of the 1st International Conference on Image Processing, Austin, TX, USA, 13-16 November 1994; Volume 2, pp. 301-305.

49. Yang, Y.Q.; Bai, J.; Tian, R.L.; Liu, N. A vehicle license plate recognition system based on fixed color collocation. In Proceedings of the 2005 International Conference on Machine Learning and Cybernetics, Guangzhou, China, 18-21 August 2005; Volume 9, pp. 5394-5397.

50. Jia, W.; Zhang, H.; He, X.; Piccardi, M. Mean shift for accurate license plate localization. In Proceedings of the 2005 IEEE Intelligent Transportation Systems, Vienna, Austria, 16 September 2005; pp. 566-571.

51. Jia, W.; Zhang, H.; He, X. Region-based license plate detection. J. Netw. Comput. Appl. 2007, 30, 1324-1333. [CrossRef]

52. Pan, L.; Li, S. A new license plate extraction framework based on fast mean shift. In Proceedings of the International Conference on Image Processing and Pattern Recognition in Industrial Engineering. International Society for Optics and Photonics, Xi'an, China, 19 August 2010; Volume 7820, p. 782007.

53. Wang, F.; Man, L.; Wang, B.; Xiao, Y.; Pan, W.; Lu, X. Fuzzy-based algorithm for color recognition of license plates. Pattern Recognit. Lett. 2008, 29, 1007-1020. [CrossRef]

54. Deb, K.; Jo, K.H. A vehicle license plate detection method for intelligent transportation system applications. Cybern. Syst. Int. J. 2009, 40, 689-705. [CrossRef]

55. Huang, D.; Shan, C.; Ardabilian, M.; Wang, Y.; Chen, L. Local binary patterns and its application to facial image analysis: A survey. IEEE Trans. Syst. Man Cybern. Part C (Appl. Rev.) 2011, 41, 765-781. [CrossRef]

56. Teoh, S.S.; Bräunl, T. Performance evaluation of HOG and Gabor features for vision-based vehicle detection. In Proceedings of the 2015 IEEE International Conference on Control System, Computing and Engineering (ICCSCE),Penang, Malaysia, 19-27 November 2015; pp. 66-71.

57. Soh, Y.S.; Chun, B.T.; Yoon, H.S. Design of real time vehicle identification system. In Proceedings of the IEEE International Conference on Systems, Man and Cybernetics, San Antonio, TX, USA, 2-5 October 1994; Volume 3, pp. $2147-2152$.

58. Agui, T.; Choi, H.; Nakajima, M. A method of number plate extraction using a fast pyramid hierarchical Hough transformation. IEICE Trans. Info. Sys. 1987, 70, 1383-1389. (In Japanese)

59. Nathan, V.S.L.; Ramkumar, J.; Priya, S.K. New approaches for license plate recognition system. In Proceedings of the International Conference on Intelligent Sensing and Information Processing, Chennai, India, 4-7 January 2004; pp. 149-152.

60. Seetharaman, V.; Sathyakhala, A.; Vidhya, N.; Sunder, P. License plate recognition system using hybrid neural networks. In Proceedings of the IEEE Annual Meeting of the Fuzzy Information, Banff, AB, Canada, 27-30 June 2004; Volume 1, pp. 363-366.

61. Anagnostopoulos, C.; Alexandropoulos, T.; Boutas, S.; Loumos, V.; Kayafas, E. A template-guided approach to vehicle surveillance and access control. In Proceedings of the IEEE Conference on Advanced Video and Signal Based Surveillance,Como, Italy, 15-16 September 2005; pp. 534-539.

62. Hsieh, C.T.; Juan, Y.S.; Hung, K.M. Multiple license plate detection for complex background. In Proceedings of the 19th International Conference on Advanced Information Networking and Applications (AINA'05) Volume 1 (AINA papers), Taipei, Taiwan, 28-30 March 2005; Volume 2, pp. 389-392.

63. Sankari, M.; Bremananth, R.; Meena, C. A Robust Diverged Localization and Recognition of License Registration Characters. Int. J. Electr. Comput. Eng. 2013, 6, 1225-1232.

64. Zunino, R.; Rovetta, S. Visual location of license plates by vector quantization. In Proceedings of the 1999 IEEE International Symposium on Circuits and Systems (ISCAS), Orlando, FL, USA, 30 May 1999; Volume 4, pp. 135-138.

65. Anagnostopoulos, C.N.E.; Anagnostopoulos, I.E.; Loumos, V.; Kayafas, E. A license plate-recognition algorithm for intelligent transportation system applications. IEEE Trans. Intell. Transp. Syst. 2006, 7, 377-392. [CrossRef] 
66. Caner, H.; Gecim, H.S.; Alkar, A.Z. Efficient embedded neural-network-based license plate recognition system. IEEE Trans. Veh. Technol. 2008, 57, 2675-2683. [CrossRef]

67. Kahraman, F.; Kurt, B.; Gökmen, M. License plate character segmentation based on the gabor transform and vector quantization. In International Symposium on Computer and Information Sciences; Springer: Antalya, Turkey, 3-5 November 2003; pp. 381-388.

68. Wang, Y.R.; Lin, W.H.; Horng, S.J. A sliding window technique for efficient license plate localization based on discrete wavelet transform. Expert Syst. Appl. 2011, 38, 3142-3146. [CrossRef]

69. Zhang, H.; Jia, W.; He, X.; Wu, Q. Learning-based license plate detection using global and local features. In Proceedings of the 18th International Conference on Pattern Recognition (ICPR'06), Hong Kong, China, 20-24 August 2006; Volume 2, pp. $1102-1105$.

70. Dlagnekov, L. License Plate Detection Using Adaboost; Computer Science and Engineering Department: San Diego, CA, USA, 2004.

71. Wang, S.Z.; Lee, H.J. A cascade framework for a real-time statistical plate recognition system. IEEE Trans. Inf. Forensics Secur. 2007, 2, 267-282. [CrossRef]

72. Matas, J.; Zimmermann, K. Unconstrained licence plate and text localization and recognition. In Proceedings of the 2005 IEEE Intelligent Transportation Systems, Vienna, Austria, 16 September 2005; pp. 225-230.

73. Alegria, F.; Girao, P.S. Vehicle plate recognition for wireless traffic control and law enforcement system. In Proceedings of the 2006 IEEE International Conference on Industrial Technology, Mumbai, India, 15-17 December 2006; pp. $1800-1804$.

74. Hontani, H.; Koga, T. Character extraction method without prior knowledge on size and position information. In Proceedings of the IEEE International Vehicle Electronics Conference 2001. IVEC 2001 (Cat. No.01EX522), Tottori, Japan, 25-28 September 2001; pp. 67-72. [CrossRef]

75. Cho, B.; Ryu, S.; Shin, D.; Jung, J. License plate extraction method for identification of vehicle violations at a railway level crossing. Int. J. Automot. Technol. 2011, 12, 281-289. [CrossRef]

76. Ho, W.T.; Lim, H.W.; Tay, Y.H. Two-stage license plate detection using gentle Adaboost and SIFT-SVM. In Proceedings of the 2009 First Asian Conference on Intelligent Information and Database Systems, Dong hoi, Vietnam, 1-3 April 2009; pp. 109-114.

77. Le, W.; Li, S. A hybrid license plate extraction method for complex scenes. In Proceedings of the 18th International Conference on Pattern Recognition (ICPR'06), Hong Kong, China, 20-24 August 2006; Volume 2, pp. 324-327.

78. Laroca, R.; Severo, E.; Zanlorensi, L.A.; Oliveira, L.S.; Gonçalves, G.R.; Schwartz, W.R.; Menotti, D. A robust real-time automatic license plate recognition based on the YOLO detector. In Proceedings of the 2018 International Joint Conference on Neural Networks (IJCNN), Rio de Janeiro, Brazil, 8-13 July 2018; pp. 1-10.

79. Masood, S.Z.; Shu, G.; Dehghan, A.; Ortiz, E.G. License plate detection and recognition using deeply learned convolutional neural networks. arXiv 2017, arXiv:1703.07330.

80. OpenALPR. OpenALPR Rekor Solutions Suite. Available online: http://www.openalpr.com/cloud-api.html (accessed on 29 December 2020).

81. Bulan, O.; Kozitsky, V.; Ramesh, P.; Shreve, M. Segmentation-and annotation-free license plate recognition with deep localization and failure identification. IEEE Trans. Intell. Transp. Syst. 2017, 18, 2351-2363. [CrossRef]

82. Nijhuis, J.; Ter Brugge, M.; Helmholt, K.; Pluim, J.; Spaanenburg, L.; Venema, R.S.; Westenberg, M. Car license plate recognition with neural networks and fuzzy logic. In Proceedings of the ICNN'95-International Conference on Neural Networks, Australia, 27 November 1995; Volume 5, pp. 2232-2236.

83. Ter Brugge, M.; Stevens, J.; Nijhuis, J.; Spaanenburg, L. License plate recognition using DTCNNs. In Proceedings of the 1998 Fifth IEEE International Workshop on Cellular Neural Networks and their Applications. Proceedings (Cat. No. 98TH8359), London, UK, 14-17 April 1998; pp. 212-217.

84. Xu, J.F.; Li, S.F.; Yu, M.S. Car license plate extraction using color and edge information. In Proceedings of the 2004 International Conference on Machine Learning and Cybernetics (IEEE Cat. No. 04EX826), Shanghai, China , 26-29 August 2004; Volume 6, pp. 3904-3907.

85. Park, S.H.; Kim, K.I.; Jung, K.; Kim, H.J. Locating car license plates using neural networks. Electron. Lett. 1999, $35,1475-1477$. [CrossRef]

86. Kim, K.K.; Kim, K.I.; Kim, J.; Kim, H.J. Learning-based approach for license plate recognition. In Proceedings of the Proceedings of the 2000 IEEE Signal Processing Society Workshop (Cat. No. 00TH8501), Neural Networks for Signal Processing X, Sydney, NSW, Australia, 11-13 December 2000; Volume 2, pp. 614-623.

87. Wang, M.L.; Liu, Y.H.; Liao, B.Y.; Lin, Y.S.; Horng, M.F. A vehicle license plate recognition system based on spatial/frequency domain filtering and neural networks. In International Conference on Computational Collective Intelligence; Springer: Kaohsiung, Taiwan, 10-12 November 2010; pp. 63-70.

88. Porikli, F.; Kocak, T. Robust license plate detection using covariance descriptor in a neural network framework. In Proceedings of the 2006 IEEE International Conference on Video and Signal Based Surveillance, Sydney, NSW, Australia, 22-24 November 2006; pp. 107-107.

89. Chen, Z.X.; Liu, C.Y.; Chang, F.L.; Wang, G.Y. Automatic license-plate location and recognition based on feature salience. IEEE Trans. Veh. Technol. 2009, 58, 3781-3785. [CrossRef]

90. Mao, S.; Huang, X.; Wang, M. An adaptive method for Chinese license plate location. In Proceedings of the 20108 th World Congress on Intelligent Control and Automation, Jinan, China, 7-9 July 2010; pp. 6173-6177. 
91. Wu, M.K.; Wei, J.S.; Shih, H.C.; Ho, C.C. License plate detection based on 2-level 2D Haar wavelet transform and edge density verification. In Proceedings of the 2009 IEEE International Symposium on Industrial Electronics, Seoul, Korea (South), 5-8 July 2009; pp. 1699-1704.

92. Lee, Y.; Song, T.; Ku, B.; Jeon, S.; Han, D.K.; Ko, H. License plate detection using local structure patterns. In Proceedings of the 2010 7th IEEE International Conference on Advanced Video and Signal Based Surveillance, Boston, MA, USA, 29 August 2010; pp. 574-579.

93. Montazzolli, S.; Jung, C. Real-time brazilian license plate detection and recognition using deep convolutional neural networks. In Proceedings of the 2017 30th SIBGRAPI conference on graphics, patterns and images (SIBGRAPI), Niteroi, Brazil, 17-20 October 2017; pp. 55-62.

94. Li, H.; Wang, P.; You, M.; Shen, C. Reading car license plates using deep neural networks. Image Vis. Comput. 2018, 72, 14-23. [CrossRef]

95. Li, H.; Wang, P.; Shen, C. Toward end-to-end car license plate detection and recognition with deep neural networks. IEEE Trans. Intell. Transp. Syst. 2018, 20, 1126-1136. [CrossRef]

96. Xu, X.; Wang, Z.; Zhang, Y.; Liang, Y. A method of multi-view vehicle license plates location based on rectangle features. In Proceedings of the 2006 8th international Conference on Signal Processing, Guilin, China, 16-20 November 2006 ; Volume 3.

97. Pan, M.S.; Yan, J.B.; Xiao, Z.H. Vehicle license plate character segmentation. Int. J. Autom. Comput. 2008, 5, 425-432. [CrossRef]

98. Pan, M.S.; Xiong, Q.; Yan, J.B. A new method for correcting vehicle license plate tilt. Int. J. Autom. Comput. 2009, 6, 210-216. [CrossRef]

99. Zhang, Y.; Zhang, C. A new algorithm for character segmentation of license plate. In Proceedings of the IEEE IV2003 Intelligent Vehicles Symposium. Proceedings (Cat. No. 03TH8683), Columbus, OH, USA, 9-11 June 2003; pp. 106-109.

100. Llorens, D.; Marzal, A.; Palazon, V.; Vilar, J.M. Car license plates extraction and recognition based on connected components analysis and HMM decoding. In Iberian Conference on Pattern Recognition and Image Analysis; Springer: Estoril, Portugal, 7-9 June 2005; pp. 571-578.

101. Coetzee, C.; Botha, C.; Weber, D. PC based number plate recognition system. In Proceedings of the IEEE International Symposium on Industrial Electronics. Proceedings. ISIE'98 (Cat. No. 98TH8357), Pretoria, South Africa, 7-10 July 1998; Volume 2, pp. 605-610.

102. Comelli, P.; Ferragina, P.; Granieri, M.N.; Stabile, F. Optical recognition of motor vehicle license plates. IEEE Trans. Veh. Technol. 1995, 44, 790-799. [CrossRef]

103. Omran, S.S.; Jarallah, J.A. Iraqi License Plate Localization and Recognition System Using Neural Network. In Proceedings of the 2017 Second Al-Sadiq International Conference on Multidisciplinary in IT and Communication Science and Applications (AIC-MITCSA), Baghdad, Iraq, 30-31 December 2017; pp. 73-78.

104. Sanyuan, Z.; Mingli, Z.; Xiuzi, Y. Car plate character extraction under complicated environment. In Proceedings of the 2004 IEEE International Conference on Systems, Man and Cybernetics (IEEE Cat. No. 04CH37583), The Hague, Netherlands, 10-13 October 2004; Volume 5, pp. 4722-4726.

105. Duan, T.D.; Du, T.H.; Phuoc, T.V.; Hoang, N.V. Building an automatic vehicle license plate recognition system. In Proceedings of the International Conference Computer Science RIVF. Citeseer, Can Tho, Vietnam, 21-24 February 2005; Volume 1, pp. 59-63.

106. Qin, Z.; Shi, S.; Xu, J.; Fu, H. Method of license plate location based on corner feature. In Proceedings of the 20066 th World Congress on Intelligent Control and Automation, Dalian, China, 21-23 June 2006; Volume 2, pp. 8645-8649.

107. Cheng, Y.; Lu, J.; Yahagi, T. Car license plate recognition based on the combination of principal components analysis and radial basis function networks. In Proceedings of the 7th International Conference on Signal Processing, Beijing, China, 31 August 2004; Volume 2, pp. 1455-1458.

108. Chowdhury, S.; Das, A.; Punitha, P. Projection Profile based Number Plate Localization and Recognition. Comput. Sci. Inf. Technol. 2016, 185-200. [CrossRef]

109. Hegt, H.A.; De La Haye, R.J.; Khan, N.A. A high performance license plate recognition system. In Proceedings of the 1998 IEEE International Conference on Systems, Man, and Cybernetics (Cat. No. 98CH36218), San Diego, CA, USA, 14 October 1998; Volume 5, pp. 4357-4362.

110. Shan, B. Vehicle License Plate Recognition Based on Text-line Construction and Multilevel RBF Neural Network. JCP 2011, 6, 246-253. [CrossRef]

111. Barroso, J.; Dagless, E.; Rafael, A.; Bulas-Cruz, J. Number plate reading using computer vision. In Proceedings of the Proceeding of the IEEE International Symposium on Industrial Electronics, ISIE'97, Guimaraes, Portugal, 7-11 July 1997; pp. 761-766.

112. Jia, Y.; Gonnot, T.; Saniie, J. Design flow of vehicle license plate reader based on RGB color extractor. In Proceedings of the 2016 IEEE International Conference on Electro Information Technology (EIT), Grand Forks, ND, USA, 19-21 May 2016; pp. 0494-0498.

113. Paliy, I.; Turchenko, V.; Koval, V.; Sachenko, A.; Markowsky, G. Approach to recognition of license plate numbers using neural networks. In Proceedings of the 2004 IEEE International Joint Conference on Neural Networks (IEEE Cat. No. 04CH37541), Budapest, Hungary, 25-29 July 2004; Volume 4, pp. 2965-2970.

114. Gao, Q.; Wang, X.; Xie, G. License plate recognition based on prior knowledge. In Proceedings of the 2007 IEEE International Conference on Automation and Logistics, Jinan, China, 18-21 AugustJaipur, India, 9-10 May 2007; pp. $2964-2968$.

115. Guo, J.M.; Liu, Y.F. License plate localization and character segmentation with feedback self-learning and hybrid binarization techniques. IEEE Trans. Veh. Technol. 2008, 57, 1417-1424. 
116. Singh, V.; Srivastava, A.; Kumar, S.; Ghosh, R. A Structural Feature Based Automatic Vehicle Classification System at Toll Plaza. In International Conference on Internet of Things and Connected Technologies; Springer: Jaipur, India, 9-10 May 2019; pp. 1-10.

117. Lin, N.H.; Aung, Y.L.; Khaing, W.K. Automatic vehicle license plate recognition system for smart transportation. In Proceedings of the 2018 IEEE International Conference on Internet of Things and Intelligence System (IOTAIS), Bali, Indonesia, 1-3 November 2018; pp. 97-103.

118. Nomura, S.; Yamanaka, K.; Katai, O.; Kawakami, H. A new method for degraded color image binarization based on adaptive lightning on grayscale versions. IEICE Trans. Inf. Syst. 2004, 87, 1012-1020.

119. Nomura, S.; Yamanaka, K.; Katai, O.; Kawakami, H.; Shiose, T. A novel adaptive morphological approach for degraded character image segmentation. Pattern Recognit. 2005, 38, 1961-1975. [CrossRef]

120. Kang, D.J. Dynamic programming-based method for extraction of license plate numbers of speeding vehicles on the highway. Int. J. Automot. Technol. 2009, 10, 205-210. [CrossRef]

121. Yogheedha, K.; Nasir, A.; Jaafar, H.; Mamduh, S. Automatic vehicle license plate recognition system based on image processing and template matching approach. In Proceedings of the 2018 International Conference on Computational Approach in Smart Systems Design and Applications (ICASSDA), Kuching, Malaysia, 15-17 August 2018; pp. 1-8.

122. Shuang-tong, T.; Wen-ju, L. Number and letter character recognition of vehicle license plate based on edge Hausdorff distance. In Proceedings of the Sixth International Conference on Parallel and Distributed Computing Applications and Technologies (PDCAT'05), Dalian, China, 5-8 December 2005; pp. 850-852.

123. Xiaobo, L.; Xiaojing, L.; Wei, H. Vehicle license plate character recognition. In Proceedings of the International Conference on Neural Networks and Signal Processing,Nanjing, China , 14-17 December 2003; Volume 2, pp. 1066-1069.

124. Naito, T.; Tsukada, T.; Yamada, K.; Kozuka, K.; Yamamoto, S. Robust license-plate recognition method for passing vehicles under outside environment. IEEE Trans. Veh. Technol. 2000, 49, 2309-2319. [CrossRef]

125. Desai, G.G.; Bartakke, P.P. Real-Time Implementation Of Indian License Plate Recognition System. In Proceedings of the 2018 IEEE Punecon, Pune, India, 30 November 2018; pp. 1-5.

126. Sasi, A.; Sharma, S.; Cheeran, A.N. Automatic car number plate recognition. In Proceedings of the 2017 International Conference on Innovations in Information, Embedded and Communication Systems (ICIIECS), Coimbatore, India, 17-18 March 2017; pp. 1-6.

127. Li, M.; Sun, T.; Liu, H. Image Recognition of Steel Plate Based on an improved Support Vector Machine. In Proceedings of the 2018 IEEE International Conference on Information and Automation (ICIA), Wuyishan, China, 11-13 August 2018; pp. 1411-1415.

128. Al-Shemarry, M.S.; Li, Y. Developing Learning-Based Preprocessing Methods for Detecting Complicated Vehicle Licence Plates. IEEE Access 2020, 8, 170951-170966. [CrossRef]

129. Dia, Y.; Zheng, N.; Zhang, X.; Xuan, G. Automatic recognition of province name on the license plate of moving vehicle. In Proceedings of the 9th International Conference on Pattern Recognition, Rome, Italy, 14-17 May 1988; pp. 927-929.

130. Ko, M.A.; Kim, Y.M. A simple OCR method from strong perspective view. In Proceedings of the 33rd Applied Imagery Pattern Recognition Workshop (AIPR'04), Washington, DC, USA, 13-15 October 2004; pp. 235-240.

131. Kim, M.K.; Kwon, Y.B. Multi-font and multi-size character recognition based on the sampling and quantization of an unwrapped contour. In Proceedings of the 13th International Conference on Pattern Recognition, Vienna, Austria, 25-29 August 1996; Volume 3, pp. 170-174.

132. Hu, P.; Zhao, Y.; Yang, Z.; Wang, J. Recognition of gray character using gabor filters. In Proceedings of the Fifth International Conference on Information Fusion. FUSION 2002.(IEEE Cat. No. 02EX5997), Annapolis, MD, USA, 8-11 July 2002; Volume 1, pp. 419-424.

133. Abdullah, S.N.H.S.; Khalid, M.; Yusof, R.; Omar, K. License plate recognition using multi-cluster and multilayer neural networks. In Proceedings of the 2006 2nd International Conference on Information \& Communication Technologies, Damascus, Syria, 24-28 April 2006; Volume 1, pp. 1818-1823.

134. Abdullah, S.N.H.S.; Khalid, M.; Yusof, R.; Omar, K. Comparison of feature extractors in license plate recognition. In Proceedings of the First Asia International Conference on Modelling \& Simulation (AMS'07), Phyket, Thailand, 27-30 March 2007; pp. 502-506.

135. Duangphasuk, P.; Thammano, A. Thai vehicle license plate recognition using the hierarchical cross-correlation ARTMAP. In Proceedings of the 2006 3rd International IEEE Conference Intelligent Systems, London, UK, 4-6 September 2006 ; pp. 652-655.

136. Jiao, J.; Ye, Q.; Huang, Q. A configurable method for multi-style license plate recognition. Pattern Recognit. 2009, 42, 358-369. [CrossRef]

137. Amit, Y.; Geman, D.; Fan, X. A coarse-to-fine strategy for multiclass shape detection. IEEE Trans. Pattern Anal. Mach. Intell. 2004, 26, 1606-1621. [CrossRef]

138. Amit, Y. A neural network architecture for visual selection. Neural Comput. 2000, 12, 1141-1164. [CrossRef]

139. Amit, Y.; Geman, D. A computational model for visual selection. Neural Comput. 1999, 11, 1691-1715. [CrossRef] [PubMed]

140. Kraisin, S.; Kaothanthong, N. Accuracy Improvement of A Province Name Recognition on Thai License Plate. In Proceedings of the 2018 International Joint Symposium on Artificial Intelligence and Natural Language Processing (iSAI-NLP), Pattaya, Thailand, 15-17 November 2018; pp. 1-6.

141. Vaishnav, A.; Mandot, M. An integrated automatic number plate recognition for recognizing multi language fonts. In Proceedings of the 2018 7th International Conference on Reliability, Infocom Technologies and Optimization (Trends and Future Directions)(ICRITO), Noida, India, 29-31 August 2018; pp. 551-556. 
142. Molina-Moreno, M.; González-Díaz, I.; Díaz-de María, F. Efficient scale-adaptive license plate detection system. IEEE Trans. Intell. Transp. Syst. 2018, 20, 2109-2121. [CrossRef]

143. Mutholib, A.; Gunawan, T.S.; Kartiwi, M. Design and implementation of automatic number plate recognition on android platform. In Proceedings of the 2012 International Conference on Computer and Communication Engineering (ICCCE), Kuala Lumpur, Malaysia, 3-5 July 2012; pp. 540-543.

144. Ashtari, A.H.; Nordin, M.J.; Fathy, M. An Iranian license plate recognition system based on color features. IEEE Trans. Intell. Transp. Syst. 2014, 15, 1690-1705. [CrossRef]

145. Kakani, B.V.; Gandhi, D.; Jani, S. Improved OCR based automatic vehicle number plate recognition using features trained neural network. In Proceedings of the 2017 8th international conference on computing, communication and networking technologies (ICCCNT), Delhi, India, 3-5 July 2017; pp. 1-6.

146. How, D.N.T.; Sahari, K.S.M. Character recognition of Malaysian vehicle license plate with deep convolutional neural networks. In Proceedings of the 2016 IEEE International Symposium on Robotics and Intelligent Sensors (IRIS), Tokyo, Japan, 17-20 December 2016; pp. 1-5.

147. Lee, S.; Son, K.; Kim, H.; Park, J. Car plate recognition based on CNN using embedded system with GPU. In Proceedings of the 2017 10th International Conference on Human System Interactions (HSI), Ulsan, Korea (South), 17-19 July 2017 ; pp. $239-241$.

148. Quiros, A.R.F.; Bedruz, R.A.; Uy, A.C.; Abad, A.; Bandala, A.; Dadios, E.P.; Fernando, A. A kNN-based approach for the machine vision of character recognition of license plate numbers. In Proceedings of the TENCON 2017-2017 IEEE Region 10 Conference, Penang, Malaysia, 5-8 November 2017; pp. 1081-1086.

149. Selmi, Z.; Halima, M.B.; Alimi, A.M. Deep learning system for automatic license plate detection and recognition. In Proceedings of the 2017 14th IAPR international conference on document analysis and recognition (ICDAR), Kyoto, Japan, 9-15 November 2017; Volume 1, pp. 1132-1138.

150. Mondal, M.; Mondal, P.; Saha, N.; Chattopadhyay, P. Automatic number plate recognition using CNN based self synthesized feature learning. In Proceedings of the 2017 IEEE Calcutta Conference (CALCON), Kolkata, India, 2-3 December 2017; pp. 378-381.

151. Liu, J.; Li, X.; Zhang, H.; Liu, C.; Dou, L.; Ju, L. An implementation of number plate recognition without segmentation using convolutional neural network. In Proceedings of the 2017 IEEE 19th International Conference on High Performance Computing and Communications; IEEE 15th International Conference on Smart City; IEEE 3rd International Conference on Data Science and Systems (HPCC/SmartCity/DSS), Bangkok, Thailand, 18-20 December 2017; pp. 246-253.

152. Huang, Z.K.; Hou, L.Y. Chinese License Plate Detection Based on Deep Neural Network. In Proceedings of the 2018 International Conference on Control and Robots (ICCR),Hong Kong, China, 15-17 September 2018; pp. 84-88.

153. Ruili, J.; Haocong, W.; Han, W.; O'Connell, E.; McGrath, S. Smart parking system using image processing and artificial intelligence. In Proceedings of the 2018 12th International Conference on Sensing Technology (ICST), Limerick, Ireland, 4-6 December 2018; pp. 232-235.

154. Huang, S.; Xu, H.; Xia, X.; Zhang, Y. End-to-end vessel plate number detection and recognition using deep convolutional neural networks and LSTMs. In Proceedings of the 2018 11th International Symposium on Computational Intelligence and Design (ISCID), Hangzhou, China, 8-9 December 2018; Volume 1, pp. 195-199.

155. Rabbani, G.; Islam, M.A.; Azim, M.A.; Islam, M.K.; Rahman, M.M. Bangladeshi license plate detection and recognition with morphological operation and convolution neural network. In Proceedings of the 2018 21st International Conference of Computer and Information Technology (ICCIT), Dhaka, Bangladesh, 21-23 December 2018; pp. 1-5.

156. Imaduddin, H.; Anwar, M.K.; Perdana, M.I.; Sulistijono, I.A.; Risnumawan, A. Indonesian vehicle license plate number detection using deep convolutional neural network. In Proceedings of the 2018 International Electronics Symposium on Knowledge Creation and Intelligent Computing (IES-KCIC), East Java, Indonesia, 29-30 October 2018, pp. 158-163.

157. Akhtar, Z.; Ali, R. Automatic Number Plate Recognition Using Random Forest Classifier. SN Comput. Sci. 2020, 1, 1-9. [CrossRef]

158. GONG, W.b.; SHI, Z.s.; Qiang, J. Non-Segmented Chinese License Plate Recognition Algorithm based on Deep neural Networks. In Proceedings of the 2020 Chinese Control And Decision Conference (CCDC), Hefei, China, 20-24 August 2020 ; pp. 66-71.

159. Silva, S.M.; Jung, C.R. Real-time license plate detection and recognition using deep convolutional neural networks. J. Vis. Commun. Image Represent. 2020, 71, 102773. [CrossRef]

160. Pustokhina, I.V.; Pustokhin, D.A.; Rodrigues, J.J.; Gupta, D.; Khanna, A.; Shankar, K.; Seo, C.; Joshi, G.P. Automatic vehicle license plate recognition using optimal K-means with convolutional neural network for intelligent transportation systems. IEEE Access 2020, 8, 92907-92917. [CrossRef]

161. Shvai, N.; Hasnat, A.; Meicler, A.; Nakib, A. Accurate classification for automatic vehicle-type recognition based on ensemble classifiers. IEEE Trans. Intell. Transp. Syst. 2019, 21, 1288-1297. [CrossRef]

162. Weihong, W.; Jiaoyang, T. Research on license plate recognition algorithms based on deep learning in complex environment. IEEE Access 2020, 8, 91661-91675. [CrossRef]

163. Oliveira-Neto, F.M.; Han, L.D.; Jeong, M.K. An online self-learning algorithm for license plate matching. IEEE Trans. Intell. Transp. Syst. 2013, 14, 1806-1816. [CrossRef]

164. Deng, J.; Dong, W.; Socher, R.; Li, L.J.; Li, K.; Fei-Fei, L. Imagenet: A large-scale hierarchical image database. In Proceedings of the 2009 IEEE conference on computer vision and pattern recognition. Miami, FL, USA, 20-25 June 2009; pp. 248-255. 
165. Yang, L.; Luo, P.; Change Loy, C.; Tang, X. A large-scale car dataset for fine-grained categorization and verification. In Proceedings of the IEEE Conference on Computer Vision and Pattern Recognition, Boston, MA, USA, 7-12 June 2015; pp. $3973-3981$.

166. Xu, Z.; Yang, W.; Meng, A.; Lu, N.; Huang, H.; Ying, C.; Huang, L. Towards end-to-end license plate detection and recognition: A large dataset and baseline. In Proceedings of the European conference on computer vision (ECCV), Munich, Germany, 8-14 September 2018; pp. 255-271.

167. Tafazzoli, F.; Frigui, H.; Nishiyama, K. A large and diverse dataset for improved vehicle make and model recognition. In Proceedings of the IEEE Conference on Computer Vision and Pattern Recognition Workshops, Honolulu, HI, USA, 21-26 July 2017; pp. 1-8.

168. Gonçalves, G.R.; Diniz, M.A.; Laroca, R.; Menotti, D.; Schwartz, W.R. Real-time automatic license plate recognition through deep multi-task networks. In Proceedings of the 2018 31st SIBGRAPI Conference on Graphics, Patterns and Images (SIBGRAPI), Paraná, Brazil, 29 October-1 November 2018; pp. 110-117.

169. Hsu, G.S.; Chen, J.C.; Chung, Y.Z. Application-oriented license plate recognition. IEEE Trans. Veh. Technol. 2012, 62, 552-561. [CrossRef]

170. Krause, J.; Stark, M.; Deng, J.; Fei-Fei, L. 3d object representations for fine-grained categorization. In Proceedings of the IEEE International Conference on Computer Vision Workshops, Sydney, Australia, 3-8 December 2013; pp. 554-561.

171. Cordts, M.; Omran, M.; Ramos, S.; Rehfeld, T.; Enzweiler, M.; Benenson, R.; Franke, U.; Roth, S.; Schiele, B. The cityscapes dataset for semantic urban scene understanding. In Proceedings of the IEEE Conference on Computer Vision and Pattern Recognition, Las Vegas, Nevada, USA, 27-30 June 2016; pp. 3213-3223.

172. Weber, M. Pasadena Computational Vision at California Institute of Technology: The Caltech database. Available online: http:/ / www.vision.caltech.edu/html-files/archive.html (accessed on 2 January 2021).

173. Arróspide, J.; Salgado, L.; Nieto, M.; Mohedano, R. Homography-based ground plane detection using a single on-board camera. IET Intell. Transp. Syst. 2010, 4, 149-160. [CrossRef]

174. Ferdowsi, A.; Challita, U.; Saad, W. Deep learning for reliable mobile edge analytics in intelligent transportation systems: An overview. IEEE Veh. Technol. Mag. 2019, 14, 62-70. [CrossRef]

175. Henry, C.; Ahn, S.Y.; Lee, S.W. Multinational license plate recognition using generalized character sequence detection. IEEE Access 2020, 8, 35185-35199. [CrossRef]

176. Mohandes, M.; Deriche, M.; Ahmadi, H.; Kousa, M.; Balghonaim, A. An intelligent system for vehicle access control using RFID and ALPR technologies. Arab. J. Sci. Eng. 2016, 41, 3521-3530. [CrossRef]

177. Yang, C.H.; Tsai, H.M. Vehicle counting and speed estimation with RFID backscatter signal. In Proceedings of the 2019 IEEE Vehicular Networking Conference (VNC), Los Angeles, CA, USA, 4-6 December 2019; pp. 1-8.

178. Hadavi, S.; Rai, H.B.; Verlinde, S.; Huang, H.; Macharis, C.; Guns, T. Analyzing passenger and freight vehicle movements from automatic-Number plate recognition camera data. Eur. Transp. Res. Rev. 2020, 12, 1-17. [CrossRef] 